\title{
Growth, LONGEVITY AND PuBLIC Policy
}

\author{
GREGORY PONTHIERE
}

\author{
CESIFO WORKING PAPER NO. 1780 \\ CATEgory 5: Fiscal POLICY, MACROECONOMICS AND GROWTH \\ August 2006 \\ PRESENTED AT CESIFo AREA CONFERENCE ON \\ PUBlic SECTOR ECONOMICS, APRIL 2006
}

An electronic version of the paper may be downloaded

- from the SSRN website:

www.SSRN.com

- from the RePEc website:

www.RePEc.org

- from the CESifo website:

www.CESifo-group.de 


\title{
GROWTH, LONGEVITY AND PuBLIC POLICY
}

\begin{abstract}
This paper studies the optimal long-run public intervention in a two-period OLG model where the probability of surviving the first period and the length of the second period can be influenced by distinct policies. While the optimal size of public intervention depends on the extra-productivity of public spendings in longevity, its optimal structure is determined by (1) differences in the productivity of each policy; (2) how growth would influence each longevity aspect under laissez-faire; (3) the dependence of each longevity aspect on past achievements. Given competing effects, the optimal intervention can hardly, under additive expected lifetime utility, be strongly unbalanced.
\end{abstract}

JEL Code: O41, E13, H51, I12.

Keywords: growth, longevity, public policy, rectangularization.

\author{
Gregory Ponthiere \\ CREPP \\ University of Liege \\ Boulevard du Rectorat, 7 \\ bat. B31, Sart-Tilman \\ 4000 Liege \\ Belgium \\ G.Ponthiere@ulg.ac.be
}

I am especially grateful to Pierre Pestieau, for his invaluable suggestions on this paper, which constitutes a part of a broader, common research project. I gratefully acknowledge comments and suggestions by Alessandro Cigno, Gabrielle Demange, André Masson, Panu Poutvaara, Rick van der Ploeg, Stanley Winer, participants of the 2006 Séminaire Scientifique of the Caisse des Dépôts et Consignations in Bordeaux, and participants of the 2006 CESifo Area Conference on Public Sector Economics in Munich. The financial support of the FNRS is gratefully acknowledged. 


\section{Introduction}

The second part of the 20th century being characterized, in industrialized countries, by the coexistence of a substantial lengthening of life and a strong economic growth, it does not come as a surprise that economists have paid a particular attention to the relationship between economic growth and longevity.

Besides the numerous econometric studies on the growth-longevity relationship, longevity has been also introduced recently in growth models, in order to study the various effects of the length of life on accumulation processes, and, hence, on economic expansion. ${ }^{3}$ Whereas pioneer models examined the effects of mortality on accumulation and growth while taking survival conditions as exogenous (see Ehrlich and Lui, 1991; de la Croix and Licandro, 1999; Pecchenino and Utendorf, 1999; Zhang et al, 2001; Boucekkine et al, 2002), a more recent group of models postulated endogenous survival conditions in order to be able to analyze the reciproqual relationships between prosperity and longevity (see Chakraborty, 2004; Aisa and Pueyo, 2004; Bhattacharya and Qiao, 2005; Finlay, 2005; Pestieau et al, 2006).

Despite their differences, all those models aimed at emphasizing that, while survival conditions, by affecting the temporal horizon of individuals, influence their investment decisions (in physical and human capitals) - and thus growth -, factors affecting accumulation and growth also influence, via several distinct channels, survival conditions. Those channels may take the form of healthenhancing public expenditures (as in Chakraborty, 2004), or of health-enhancing private spendings (as in Pestieau et al, 2006), or of both (as in Bhattacharya and Qiao, 2005), private and public spendings completementing each other.

This paper shares with the existing literature the goal of examining the growth-longevity relationship: its aim is, in a first stage, to study, within a two-period OLG model, the impact of public policy on growth and longevity, and, in a second stage, to examine the definition of the optimal long-run public intervention in an economy where longevity is endogenous and can be affected by public policy. However, this study differs from the literature on three grounds.

Firstly, whereas existing models introduce longevity either under the form of a probability of survival from one period of life to another (as in Chakraborty, 2004 ), or under the form of a second period of life whose length is a fraction of unity (as in Bhattacharya and Qiao, 2005), the present paper aims at modeling both the proportion of survivors and the maximum length of life. Such a modeling is required to be able to describe the actual evolution of survival conditions, which, as shown by Figure 1 in the case of France, involves both a rise in the proportion of people reaching high ages for a fixed maximum age at death (i.e. the rectangularization process) and a rise of the maximum age at death (i.e. a shift of the survival curve to the right). ${ }^{4}$ As demographers emphasized, the rectangularization process and the rise in the maximum length of life are two

\footnotetext{
${ }^{3}$ On empirical studies, see Preston (1975, 1980), Anand and Ravallion (1993), Pritchett and Summers (1996), Easterlin (1999), and Lichtenberg (2002).

${ }^{4} \mathrm{On}$ the measurement of the rectangularization phenomenon, see Wilmoth and Horiuchi (1999), and Vallin and Berlinguer (2002).
} 
distinct phenomena, which did not occur at the same periods and with the same intensities, so that these may be influenced by different factors. ${ }^{5}$ In particular, public intervention may affect those two aspects of longevity in different ways, so that the study of optimal policy requires to distinguish those phenomena.

Secondly, the present paper, contrary to most existing models where the intervention of the government takes a single form, introduces the distinction between two kinds of public policies: on the one hand, "pure survival" expenditures, which affect the proportion of a cohort who survives the first period (e.g. public programs promoting security on roads); on the other hand, "pure longevity" expenditures, affecting the length of life of the people surviving the first period (e.g. scientific research against ageing diseases).

\section{France}

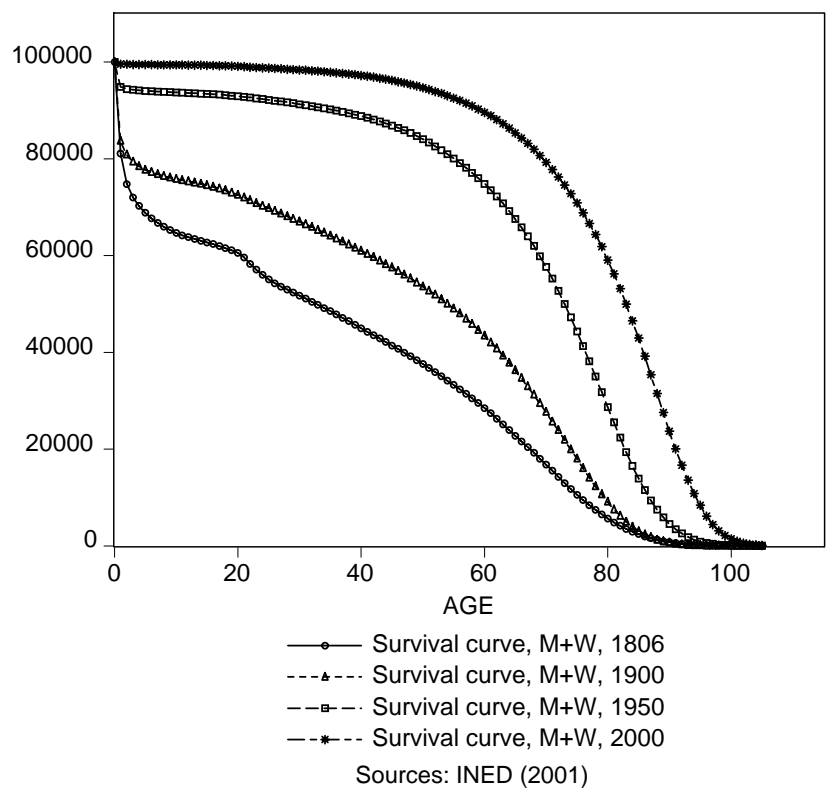

Figure 1: Period survival curves, men and women, France.

Thirdly, while existing models assume no dependence of longevity achievements on the past, a dependence on the past is postulated in this paper, in the sense that a stock of common knowledge and customs on "how to live a healthy

\footnotetext{
${ }^{5}$ For instance, Wilmoth and Horiuchi (1999) and Wilmoth et al (2000) emphasized that, in the case of Sweden, the rectangularization took place mostly between 1860 and the $1950 \mathrm{~s}$, whereas the maximum age at death started growing in a stronger way in the late 1960s. Regarding the various causes of rectangularization, see Nusselder and Mackenbach (1996).
} 
life", which affects longevity positively, is supposed to be accumulated and transmitted across generations. ${ }^{6}$ The existence of some dependency - via customs on past longevity achievements does not imply that mortality is not affected by "one-shoot" policies, which have to be implemented repeatedly. Hence, mortality is here supposed to be determined both by past achievements and by current policies.

In order to study the optimal size and structure of public intervention in an economy where the probability of survival from the first period to the second period and the length of the second period can be affected by distinct public policies, we shall, for analytical convenience, rely on a simplified model, where the production process only involves a unique generation of same-age individuals, unlike in human capital vintage models, such as Boucekkine et al (2002), where longevity is exogenous. Moreover, unlike in Pestieau et al (2006), there is no private investment in health decision: individuals cannot here affect their longevity.

This paper is organized as follows. Section 2 presents a two-period OLG model where the probability of surviving the first period is endogenous, while the length of the second period is fixed. This basic model is used to study the tax rate maximizing steady-state utility. Section 3 presents an extended framework, where the maximum length of life is endogenous. The optimal longrun allocation of governmental budget is then examined. Section 4 concludes.

\section{The basic model}

\subsection{Environment}

Let us consider a simple two-period OLG model with identical households within each generation. Each generation is denoted by its time of birth.

All individuals of a generation $t$ live the first period for sure. During that period of unitary length, all individuals work, and save some money to fund their consumption during the second period, which is a period of retirement.

However, not all members of a cohort $t$ will live the second period: only a proportion $\phi_{t+1}^{t}$ of generation $t$ will do so $\left(0 \leq \phi_{t+1}^{t} \leq 1\right){ }^{7}$ Moreover, the survivors of generation $t$ will enjoy a second period of length $\lambda_{t+1}^{t}\left(0 \leq \lambda_{t+1}^{t} \leq\right.$ 1).

To illustrate the distinction between $\phi_{t+1}^{t}$ and $\lambda_{t+1}^{t}$, Figure 2 shows the survival curves for particular values of these. If $\lambda_{t+1}^{t}$ is equal to 0.5 (i.e. the maximum length of life is 1.5$)$, and if $\phi_{t+1}^{t}$ is equal to 0.75 , the area below the survival curve is the square of side 1 and the rectangular of length 0.5 and of height 0.75 . However, if all individuals of generation $t$ survive the first period (i.e. $\phi_{t+1}^{t}=1$ ), the area below the survival curve becomes a rectangular (of

\footnotetext{
${ }^{6}$ On the influence of customs on longevity, see Vallin et al (2002).

${ }^{7}$ Given that all members of a generation live the first period entirely, this amounts to assume that the risk of death is fully concentrated at the end of the period.
} 
height 1 and of length 1.5). In that latter case, there is zero variance in the age at death.

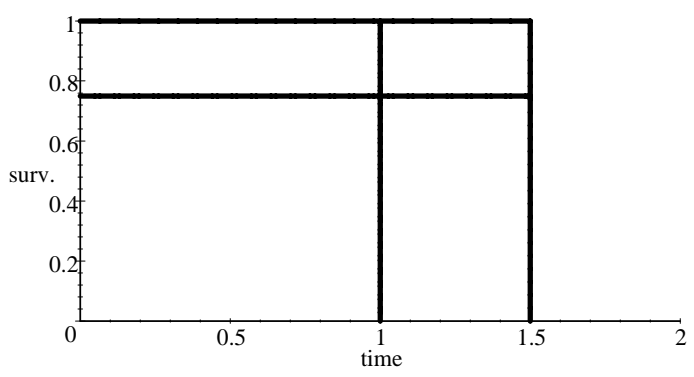

Figure 2: Survival curves.

Hence, while $\phi_{t+1}^{t}$ determines the heigth of the second rectangular, $\lambda_{t+1}^{t}$ determines its length. The sum $1+\phi_{t+1}^{t} \lambda_{t+1}^{t}$ is the well-known life expectancy (i.e. the average length of life), whereas $1+\lambda_{t+1}^{t}$ constitutes what Vallin and Berlinguer (2002) call the "limit-longevity", that is, the maximum length of life that can be lived by a member of a cohort. ${ }^{8}$

\subsection{Consumption and savings}

Consumption during the first period, denoted by $c_{t}$, is equal to:

$$
c_{t}=(1-\tau) w_{t}-s_{t}
$$

where $w_{t}$ is the wage, $\tau$ is the tax rate, while $s_{t}$ is saving. It is assumed that, at the end of the first period, each individual deposits his savings at a mutual fund. The mutual fund invests these savings in capital, and garantees a gross return equal to $\tilde{R}_{t+1}$ to the surviving old. The gross return $\tilde{R}_{t+1}$ is equal, under perfect competition, to $R_{t+1} / \phi_{t+1}^{t}$ (where $R_{t+1}$ denotes the return on invested capital). For convenience, it is also supposed that a perfect annuities market exists.

Each individual chooses the savings $s_{t}$ maximizing expected lifetime utility. Given that no one knows the actual proportion of survivors $\phi_{t+1}^{t}$ and the actual length of the second period $\lambda_{t+1}^{t}$, the saving decision is based on the longevity performances achieved by the previous cohort (i.e. $\phi_{t}^{t-1}$ and $\lambda_{t}^{t-1}$ ). Hence, under logarithmic utility, the problem is to choose $s_{t}$ to maximize:

\footnotetext{
${ }^{8}$ Although simplified - a survival curve is here reduced to 2 variables - the present model makes appear the dependence of life expectancy on the "limit-longevity".
} 


$$
\ln \left(w_{t}(1-\tau)-s_{t}\right)+\beta \lambda_{t}^{t-1} \phi_{t}^{t-1} \ln \left(\frac{1}{\lambda_{t}^{t-1} \phi_{t}^{t-1}} R_{t+1} s_{t}\right)
$$

where $\beta$ is a discount factor $(\beta>0)$. The solution to this problem is:

$$
s_{t}^{*}=\frac{\beta \lambda_{t}^{t-1} \phi_{t}^{t-1}}{1+\beta \lambda_{t}^{t-1} \phi_{t}^{t-1}}(1-\tau) w_{t}
$$

It appears here that the probability of survival and the length of the second period have a positive - but declining - influence on the propensity to save.

\subsection{Production and capital accumulation}

The production technology is specified as:

$$
Y_{t}=A K_{t}^{\alpha} L_{t}^{1-\alpha}
$$

where $A$ is a productivity parameter $(A>0), \alpha$ is a parameter $(0<\alpha<1)$, while $L_{t}$ is the labour force. In intensive terms, output per worker is:

$$
y_{t}=\frac{Y_{t}}{L_{t}}=A k_{t}^{\alpha}
$$

The labour force $L_{t}$ is supposed to grow at a constant rate $n:{ }^{9}$

$$
L_{t+1}=L_{t}(1+n)
$$

Profit maximization by firms implies:

$$
\begin{aligned}
& w_{t}=A K_{t}^{\alpha}(1-\alpha) L_{t}^{-\alpha}=(1-\alpha) A k_{t}^{\alpha} \\
& R_{t}=A \alpha K_{t}^{\alpha-1} L_{t}^{1-\alpha}=\alpha A k_{t}^{\alpha-1}
\end{aligned}
$$

It is supposed that there is a full depreciation of capital.

The capital market equilibrium $K_{t+1}=L_{t} s_{t}$ implies

$$
k_{t+1}=\frac{(1-\alpha)(1-\tau)}{1+n} A k_{t}^{\alpha} \frac{\beta \lambda_{t}^{t-1} \phi_{t}^{t-1}}{1+\beta \lambda_{t}^{t-1} \phi_{t}^{t-1}}
$$

\footnotetext{
${ }^{9}$ As Alessandro Cigno kindly pointed out to me, that assumption is, given the varying longevity, quite strong. Extending this model to connect fertility to longevity is left to future research.
} 


\subsection{Longevity}

\subsubsection{The proportion of survivors}

The proportion of survivors $\phi_{t+1}^{t}$ is supposed to be influenced by two factors.

On the one hand, it is affected by the global level of economic development. As it is widely acknowledged, richer countries are generally characterized by better survival conditions than poor countries. ${ }^{10}$ However, as Dreze and Sen (1989) and Anand and Ravallion (1993) emphasized, countries with the same level of economic development are not equally good at converting wealth in health, and public policies constitute an important channel by which the wealth of Nations affects the health of Nations. Thus, we shall distinguish here two influences of wealth on $\phi_{t+1}^{t}$ : first, the influence of prosperity independently from public intervention, which is captured by the net wage $\tilde{w}_{t}$ (i.e. net of tax); second, the influence of the government, through public expenditures denoted by $g_{t} \cdot 11$

On the other hand, $\phi_{t+1}^{t}$ is also supposed to be affected by the accumulated stock of habits and common knowledge $H_{t}$ on "how to live a healthy life", which can be regarded as a set of customs raising the probability to survive the first period. ${ }^{12}$ That set of habits may explain why two countries with the same level of economic development and the same public policy do not necessarily exhibit identical survival conditions. For convenience, $H_{t}$ is supposed to correspond to the proportion of survivors within the previous cohort (i.e. $\phi_{t}^{t-1}$ ).

Hence, a simple production function for $\phi_{t+1}^{t}$ is given by:

$$
\phi_{t+1}^{t}=1-\left[\frac{1-B \phi_{t}^{t-1}}{1+\gamma \tilde{w}_{t}+\delta g_{t}}\right]=\frac{B \phi_{t}^{t-1}+\gamma \tilde{w}_{t}+\delta g_{t}}{1+\gamma \tilde{w}_{t}+\delta g_{t}}
$$

where $B$ is the habits parameter, while $\gamma$ and $\delta$ reflect the impacts of $\tilde{w}_{t}$ and $g_{t}$ on $\phi_{t+1}^{t}$. In the rest of this paper, it is supposed that the influence of habits is, although non-negligible, weak (i.e. $0<B<1$ ), and that economic development has a globally positive influence on $\phi_{t+1}^{t}$ [i.e. $(1-\tau) \gamma+\tau \delta>0$, where $\tau$ is the tax rate], which seems to be, in the light of the empirical literature, a plausible assumption.

Expression (10) exhibits several plausible properties. First of all, the absolute impact of $\tilde{w}_{t}$ on $\phi_{t+1}^{t}$ is, provided $\gamma>0$, positive, but declining with $\tilde{w}_{t}$ and $g_{t}$. The latter property is plausible, in the light of empirical evidence (see Dreze and Sen, 1989) suggesting that public policy can serve as a substitute for $\tilde{w}_{t}$ (unlike in Bhattacharya and Qiao, 2005, where public policy and private wealth are complementary). Moreover, the impact of $g_{t}$ on $\phi_{t+1}^{t}$ is, under $\delta>0$, positive, but declining with $g_{t}$ and $\tilde{w}_{t}$. Finally, the influences of $\tilde{w}_{t}$ and $g_{t}$ on

\footnotetext{
${ }^{10}$ On this, see Pritchett and Summers (1996) for a panel data study.

${ }^{11}$ One should notice that the influence of economic development - independently of public intervention - on survival conditions is usually difficult to quantity. While prosperity seems to lead to lower mortality at the micro-level (see Valkonen, 2002), economic development at the macro-level may imply a deterioration of health (see Easterlin, 1999; Sartor, 2002).

${ }^{12} \mathrm{On}$ the central influence of habits and customs on mortality, see Vallin et al (2002).
} 
$\phi_{t+1}^{t}$ are here decreasing with $\phi_{t}^{t-1}$, reflecting that the impact of economic development on survival conditions is likely to be lower when habits are stronger. On the contrary, the positive influence of habits on $\phi_{t+1}^{t}$ is falling with $\tilde{w}_{t}$ and $g_{t}$. This captures the intuition that it is at low $\tilde{w}_{t}$ and $g_{t}$ that habits may have their largest impact on $\phi_{t+1}^{t}$.

\subsubsection{The length of the second period}

The length $\lambda_{t+1}^{t}$ of the second period of life enjoyed by survivors is supposed to be, throughout this Section, an exogenous constant $\lambda(\lambda>0)$ :

$$
\lambda_{t+1}^{t}=\lambda
$$

This assumption constitutes a strong simplification: as demographers emphasized, the evolution of mortality over time has been such that not only has a larger proportion of people reached high ages, but the maximum age at death has also grown over time. ${ }^{13}$ We shall thus endogenize $\lambda_{t+1}^{t}$ in the next Section.

\subsection{Government}

The government confines itself to collecting a tax $\tau$ on wages, and uses the revenues from taxation to fund public policies $g_{t}$ increasing the proportion of survivors of the first period $\phi_{t+1}^{t}$. Those policies can take various forms. For instance, these can be public expenditures promoting security on roads.

We shall suppose that there is no possibility of public deficit, so that:

$$
\tau w_{t}=g_{t}
$$

\subsection{Steady-states}

Fixing $k_{t+1}=k_{t}$ in the capital accumulation equation (9) allows us to derive the $k k$ locus, along which capital per worker is constant:

$$
k=\left[\frac{A(1-\alpha)(1-\tau) \beta \lambda \phi}{(1+n)(1+\beta \lambda \phi)}\right]^{\frac{1}{1-\alpha}}
$$

The first-order derivative of the $k k$ locus with respect to $\phi$ is:

$$
\frac{\partial k}{\partial \phi}=\frac{A(1-\tau) \beta \lambda\left[A(1-\alpha)(1-\tau) \beta \lambda \frac{\phi}{(1+n)(1+\beta \lambda \phi)}\right]^{\frac{\alpha}{1-\alpha}}}{(1+n)(1+\beta \lambda \phi)^{2}}>0
$$

The second-order derivative of the $k k$ locus with respect to $\phi$ is:

\footnotetext{
${ }^{13}$ See Wilmoth et al (2000) and Vallin and Berlinguer (2002).
} 


$$
\frac{\partial^{2} k}{\partial \phi^{2}}=C \lambda \frac{\left[\frac{C \lambda \phi}{(1+n)(1+\beta \lambda \phi)}\right]^{\frac{2 \alpha-1}{1-\alpha}} \frac{\alpha C \lambda(1+\beta \lambda \phi)}{(1+n)(1+\beta \lambda \phi)^{2}}-2 \lambda\left[\frac{C \lambda \phi}{(1+n)(1+\beta \lambda \phi)}\right]^{\frac{\alpha}{1-\alpha}} \beta(1-\alpha)}{(-1+\alpha)^{2}(1+n)(1+\beta \lambda \phi)^{3}}
$$

where $C \equiv A(1-\alpha)(1-\tau)$.

In a similar way, fixing $\phi_{t+1}^{t}=\phi_{t}^{t-1}$ in expression (10) allows us to derive from this the $\phi \phi$ locus, along which $\phi$ is constant:

$$
k=\left[\phi \frac{1-B}{A(1-\phi)(1-\alpha)(\gamma(1-\tau)+\delta \tau)}\right]^{\frac{1}{\alpha}}
$$

The first-order and second order derivatives of the $\phi \phi$ locus are respectively:

$$
\begin{aligned}
\frac{\partial k}{\partial \phi} & =\left[\phi \frac{1-B}{(1-\phi) E}\right]^{\frac{1-\alpha}{\alpha}} \frac{1-B}{\alpha(-1+\phi)^{2} E}>0 \\
\frac{\partial^{2} k}{\partial \phi^{2}} & =\frac{\left[\left[\frac{\phi(1-B)}{(1-\phi) E}\right]^{\frac{1-2 \alpha}{\alpha}}\left[\frac{1-B}{(-1+\phi)^{2} E}\right][(1-\phi)(1-\alpha)]+2\left[\frac{\phi(1-B)}{(1-\phi) E}\right]^{\frac{1-\alpha}{\alpha}} \alpha\right]}{(B-1)^{-1} \alpha^{2}(-1+\phi)^{3} E}
\end{aligned}
$$

where $E \equiv A(1-\alpha)[\gamma(1-\tau)+\delta \tau]$. Under the plausible assumption of a globally positive impact of economic development on $\phi$ [i.e. $\gamma(1-\tau)+\delta \tau>0$ ], those derivatives are strictly positive, so that the $\phi \phi$ locus is increasing and convex.

The issue of the existence of a steady-state can be formulated as the question of the existence of an intersection of the $k k$ and $\phi \phi$ loci. It is straightforward to see, on the basis of the $k k$ and $\phi \phi$ loci, that the two loci intersect at $(0,0)$. Regarding the existence of another, non-trivial equilibrium, two cases should be distinguished, depending on the value of $\alpha$.

If $\alpha<1 / 2$ (case 1 ), there must exist a unique non-trivial steady-state, provided the global influence of economic development on $\phi$ is positive (see Appendix A). Regarding the stability of that equilibrium, it is, under mild conditions, locally stable (see Appendix B).

If $\alpha \geq 1 / 2$, there may or may not exist a non-trivial equilibrium: as it is discussed in the Appendix, three cases should be distinguished: the existence of a unique non-trivial equilibrium (case 2a); the existence of two non-trivial equilibria (case $2 \mathrm{~b}$ ); the existence of no non-trivial equilibrium (case 2c).

Figure 3 illustrates those possible cases. On each graph, the $\phi \phi$ locus is the convex curve tending to $+\infty$ when $\phi$ tends to 1 .

Figure 3: Equilibria in the simple model $(A=20, \tau=0.1, \beta=0.99, \lambda=0.8$, $n=0, \gamma=0.1, \delta=0.3$ and $B=0.5)$. 


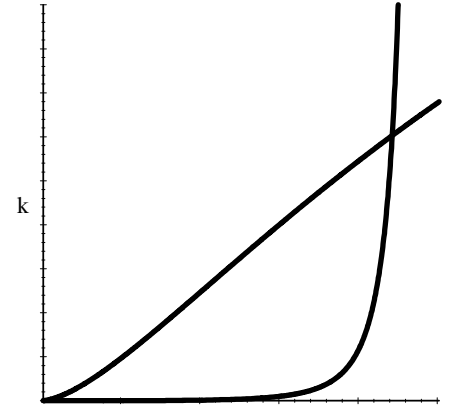

survival probability

Case 1: $\alpha=0.4$

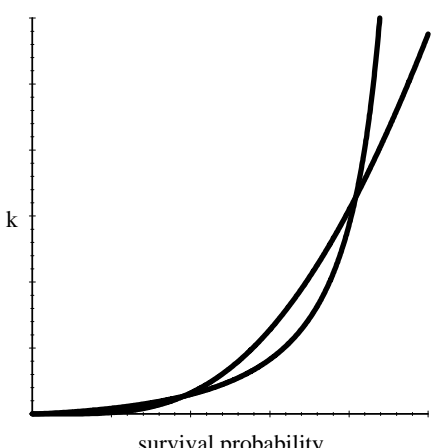

Case 2b: $\alpha=0.79$

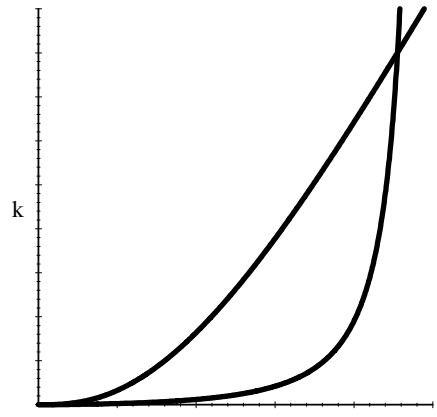

survival probability

Case 2a: $\alpha=0.65$

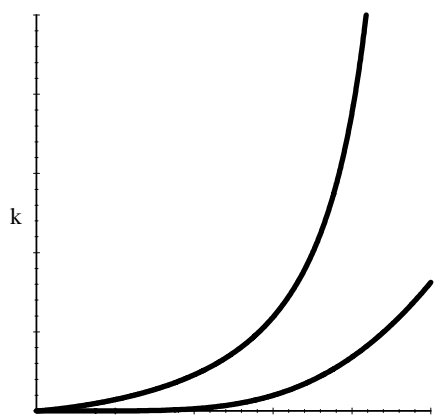

survival probability

Case 2c: $\alpha=0.85$

Regarding the stability of non-trivial equilibria, one should notice that, in cases 1 and 2 a where there is a unique non-trivial steady-state, that equilibrium is likely to be locally stable. ${ }^{14}$ To see this, it suffices to draw, on the phase diagram, the vertical and horizontal arrows on each area defined by the $k k$ and $\phi \phi$ loci. Given that $k$ tends to decrease when it is higher than the $k k$ locus, and to increase below it, whereas $\phi$ tends to increase on the left of the $\phi \phi$ locus, and to decrease on the right of it, it is clear that, around the non-trivial equilibrium, all arrows are oriented towards this, suggesting that this is locally stable.

In case $2 \mathrm{~b}$, where the $\phi \phi$ and $k k$ loci intersect twice (in addition to the trivial steady-state), it is easy to see, if one draws the arrows in the areas defined by the loci, that the intermediate equilibrium is not stable (while the high steadystate is). This observation is compatible with the existence of poverty traps: some level of development must be reached before being able to benefit from the positive dynamics and converge towards the high steady-state.

In case $2 \mathrm{c}$, there exists no non-trivial equilibrium, and drawing the arrows suggests that, in that case, the unique equilibrium (i.e. the origin of axes) is stable. Such a catastrophic scenario can be explained by the fact that, when

${ }^{14}$ See Appendix B for a formal study of stability. 
$\alpha$ is large, $1-\alpha$ tends to zero, so that savings are low, which handicaps the accumulation of capital, whatever longevity is. However, this incapacity to accumulate capital implies that high survival probabilities can be neither reached nor sustained, so that both capital and survival can only converge towards zero.

\subsection{Comparative statics}

Let us now consider the effect, on the steady-state values of $k$ and $\phi$, of changing one parameter ceteris paribus. Those effects are summarized in Table 1.

Table 1: Comparative statics results

\begin{tabular}{|ccc|}
\hline Parameter & Effect on $k^{*}$ & Effect on $\phi^{*}$ \\
$A$ & + & + \\
$\beta$ & + & + \\
$n$ & - & - \\
$\lambda$ & + & + \\
$B$ & + & + \\
$\gamma$ & + & + \\
$\delta$ & + & + \\
$\tau$ & $?$ & $?$ \\
\hline
\end{tabular}

First of all, it is interesting to notice that, provided the global effect of prosperity on survival conditions is positive, the productivity parameter $A$ and the discount factor $\beta$ have a positive effect on both $k^{*}$ and $\phi^{*}$. Under the same - plausible - assumption, the cohort growth rate $n$ has a negative effect not only on $k^{*}$, but, also, on $\phi^{*}$. On the contrary, the length $\lambda$, by favouring savings, raises the steady-state values of $k$ and $\phi$.

The parameters of the survival production function - i.e. $B, \gamma, \delta$ - affect the steady-state $\phi$ positively. All this is hardly surprising: promoting the transmission of health-preserving customs and raising the productivity of public policies can only increase $\phi$, so do attempts to make the development more "healthfriendly" (i.e. raising $\gamma$ ). Moreover, given that $\phi$ affects savings positively, such changes also raise steady-state capital.

It is important to underline the unknown effect of the tax rate $\tau$ on steadystate $k$ and $\phi$. Whereas one may expect that raising $\tau$ reduces $k^{*}$, this is not necessarily the case, because a higher $\tau$ may raise $k^{*}$ indirectly, via the positive effect of $\phi$ on the propensity to save. Moreover, raising $\tau$ does not necessarily raise $\phi^{*}$ : a higher $\tau$ may slowdown capital accumulation, which may lead to a lower $\phi^{*}$. Hence, a numerical application is required to sign the effect of $\tau$ on the steady-state.

\subsection{Numerical application: the optimal long-run tax rate}

Whereas $k$ and $\phi$ can, under some assumptions, grow "hand-in-hand", one should nonetheless keep in mind that a trade-off may exist between survival 
conditions and capital accumulation. Raising $\phi^{*}$ is not costless, and may require a non-negligible sacrifice in terms of consumption. In order to illustrate the potential trade-off between steady-state survival and consumption, we shall proceed in three stages: we shall first study the tax rate maximizing steadystate survival, then, the tax rate maximizing steady-state capital per worker, and, finally, the tax rate maximizing average steady-state utility. Results are summarized in Table 2.

The tax rate maximizing steady-state $\phi$, denoted by $\tau_{\phi}^{*}$, depends on the ratio $\gamma / \delta$, that is, on the relative "productivity" of each determinant of survival conditions. This confirms what the intuition suggests: the more survival-enhancing economic development is "naturally", the smaller is the need for governmental intervention ceteris paribus. In the light of history, there can be no doubt that, although economic expansion may affect $\phi$ positively even without governmental intervention, targeted public programs are more productive, so that $\delta$ must exceed $\gamma \cdot{ }^{15}$ However, Table 2 suggests that, if one concentrates on long-run $\phi$, this higher productivity does not suffice to justify a strictly positive $\tau_{\phi}^{*}$ : public intervention requires a significant productivity gap. For instance, given our calibration, if $\delta$ is four times as high as $\gamma, \tau_{\phi}^{*}$ is $33 \%$, but if $\delta$ is only twice as high as $\gamma$, then $\tau_{\phi}^{*}$ is zero. In the latter case, the natural impact of economic development on $\phi$ is sufficiently high compared to the influence of $g_{t}$, so that laissez-faire is optimal.

Table 2 also illustrates that the tax rate maximizing steady-state capital per worker, denoted by $\tau_{k}^{*}$, is lower than $\tau_{\phi}^{*}$. However, even if one neglects survival conditions, the optimal $\tau$ may still be strictly positive, for instance if economic development has a negative "natural" impact on $\phi$, or if its positive impact on $\phi$ is too low compared to the one of public expenditures. This is explained by the fact that $\phi$ affects savings, so that, even if $\phi$ is not valued in itself, it may be worth intervening in the economy to guarantee a sufficiently high $\phi$. Hence, the instrumental role of $\phi$ may suffice, in some circumstances, to justify public intervention. One should also notice that $\tau_{k}^{*}$ is, ceteris paribus, strictly decreasing with the productivity of public spendings.

The tax rate maximizing steady-state utility, denoted by $\tau_{u}^{*}$, lies, not surprisingly, between $\tau_{k}^{*}$ and $\tau_{\phi}^{*}$. However, the gap between $\tau_{k}^{*}$ and $\tau_{u}^{*}$, which exhibits a kind of inverted-U shape (as a function of $\gamma$ ), invites additional comments. First, one should notice that when $\gamma$ tends to be negative, the gap between $\tau_{k}^{*}$ and $\tau_{u}^{*}$ tends to be, ceteris paribus, smaller. The reason for this result lies in the fact that, the lower $\gamma$ is, the stronger is the need for intervening to sustain $\phi$ - even if one concentrates on capital only - so that the attention paid to both $k$ and $\phi$ is stronger (although $\phi$ is then purely instrumental). Hence, the extent by which the goals of maximizing long-run capital and long-run utility differ is smaller when $\gamma$ is low, so that, in that case, $\tau_{k}^{*}$ tends to converge towards $\tau_{u}^{*}$. On the contrary, when $\gamma$ becomes sufficiently high, the instrumental value of $\phi$ collapses, so that the goals of maximizing long-run utility and long-run capital differ now significantly, which is reflected by a large gap between $\tau_{k}^{*}$ and $\tau_{u}^{*}$.

\footnotetext{
${ }^{15}$ See Anand and Ravallion (1993).
} 
However, the latter statement does not imply that a higher $\gamma$ increases necessarily the gap between $\tau_{k}^{*}$ and $\tau_{u}^{*}$ : once $\gamma$ reaches some critical level with respect to $\delta$, taxation becomes undesirable as far as steady-state utility is concerned, so that both $\tau_{k}^{*}$ and $\tau_{u}^{*}$ equal zero.

Table 2: Optimal steady-state tax rates $\tau^{*}(A=20, \alpha=0.5, \beta=0.99$, $n=0)$.

\begin{tabular}{|c|c|c|c|c|c|c|c|c|c|c|c|c|c|}
\hline$\lambda$ & $\bar{B}$ & $\gamma$ & $\delta$ & $\begin{array}{l}\tau_{\phi}^{*} \\
\%\end{array}$ & $\begin{array}{l}\tau_{k}^{*} \\
\%\end{array}$ & $\begin{array}{l}\tau_{u}^{*} \\
\%\end{array}$ & $\lambda$ & $B$ & $\gamma$ & $\delta$ & $\begin{array}{l}\tau_{\phi}^{*} \\
\%\end{array}$ & $\begin{array}{l}\tau_{k}^{*} \\
\%\end{array}$ & $\begin{array}{l}\tau_{u}^{*} \\
\%\end{array}$ \\
\hline 75 & .5 & -.05 & .2 & 60 & 36 & 37 & .75 & .5 & .075 & 15 & 0 & 0 & 0 \\
\hline 75 & .5 & -.01 & .2 & 52 & 23 & 24 & .75 & .5 & .07 & .175 & 12 & & \\
\hline 75 & .5 & 0 & .2 & 50 & 18 & 20 & .75 & .5 & .075 & .2 & 20 & & \\
\hline .75 & .5 & .01 & .2 & 47 & 14 & 16 & .75 & .5 & .075 & .3 & 33 & & \\
\hline 75 & .5 & .025 & .2 & 43 & 5 & & .75 & .5 & .075 & .4 & 38 & 0 & \\
\hline .75 & .5 & .035 & .2 & 39 & 0 & 2 & .75 & .5 & .075. & .5 & 41 & 0 & 0 \\
\hline 75 & .5 & .05 & .2 & 33 & 0 & 0 & .75 & .5 & .07 & .75 & 44 & 0 & \\
\hline 75 & .5 & .075. & .2 & 20 & 0 & 0 & .75 & .5 & .075. & .95 & 46 & 0 & 2 \\
\hline 75 & .5 & .085 & .2 & 13 & 0 & & .75 & .5 & 0 & .3 & 50 & 15 & 17 \\
\hline 75 & .5 & .1 & .2 & 0 & 0 & 0 & .75 & .5 & -.01 & .3 & 52 & 18 & 20 \\
\hline .25 & .5 & .075 & .2 & 20 & 0 & & .75 & .01 & .07 & .2 & 20 & 0 & 0 \\
\hline .5 & .5 & .075 & .2 & 20 & 0 & 0 & .75 & .25 & .075 & .2 & 20 & 0 & 0 \\
\hline .75 & .5 & .075 & .2 & 20 & 0 & 0 & .75 & .5 & .075 & .2 & 20 & 0 & 0 \\
\hline 1 & .5 & .075 & .2 & 20 & 0 & 0 & .75 & .99 & .075. & .2 & 20 & 0 & 0 \\
\hline
\end{tabular}

The second part of Table 2 also illustrates that, whereas $\tau_{\phi}^{*}$ is determined exclusively by the ratio $\gamma / \delta$, this is not the case with $\tau_{u}^{*}$, which depends - as $\tau_{k}^{*}$ - on the values of $\gamma$ and $\delta$, and not only on their ratio. Indeed, whereas the optimal tax rate is $20 \%$ under $\gamma$ equal to 0 and $\delta$ equal to $0.2, \tau_{u}^{*}$ is equal to only $17 \%$ once $\delta$ is equal to 0.3 ( $\gamma$ remaining fixed). Hence, from the long-run perspective, a rise in the productivity of the State implies necessarily a fall in the size of the State: once this is more productive, keeping its size constant would lead to a waste of resources and, in fine, a waste of utility. This suggests that $\tau_{u}^{*}$ is higher in countries where the State is less productive (e.g. in developing countries).

To summarize, this short discussion emphasizes that the optimal tax rate depends crucially on how "free" economic development and governmental intervention affect survival conditions. This conclusion does not constitute a surprise, but, in the light of the lack of consensus of empirical studies on the determinants of mortality, this conclusion highlights the difficulty to know whether actual public policies are optimal from a long-run perspective. It is important to stress that, for that purpose, knowing the extra-value added by public intervention does not suffice. The estimation of $\tau_{u}^{*}$ requires additional information on the "natural" influence of economic development, which remains hard to estimate. ${ }^{16}$

${ }^{16}$ The natural influence of economic development on mortality is hard to quantify, because 


\section{Public policy with two instruments}

Whereas Section 2 postulated that the maximum length of life $1+\lambda_{t+1}^{t}$ is constant over time, this assumption constitutes, in the light of history, a strong simplification: during the last two centuries, there has been a strong rise not only in the proportion of people reaching high ages, but, also, in the maximum age at death. ${ }^{17}$ Hence, although there has been, in the industrialized world, a strong rectangularization - i.e. $\phi_{t+1}^{t}$ grew more strongly than $\lambda_{t+1}^{t}$ - there is a need for endogenizing $\lambda_{t+1}^{t}$. This task will allow us to examine the structure of the optimal public intervention, between policies raising the proportion of survivors $\phi_{t+1}^{t}$ and policies increasing the maximum longevity $1+\lambda_{t+1}^{t}$.

\subsection{Endogenous maximum length of life}

We shall now suppose that $\lambda_{t+1}^{t}$ is not constant, but can be affected either by the general prosperity, captured by the untaxed wage $\tilde{w}_{t}$, or by specific public policies (e.g. medical research against ageing diseases), denoted by $r_{t}$. Moreover, we shall suppose that $\lambda_{t+1}^{t}$ can also be influenced by the accumulated stock of common knowledge and habits on "how to live a long life", approximated by the length of the second period enjoyed by the previous generation $\lambda_{t}^{t-1} .18$ Hence, we shall postulate that $\lambda_{t+1}^{t}$ is given by:

$$
\lambda_{t+1}^{t}=1-\left[\frac{1-R \lambda_{t}^{t-1}}{1+\varepsilon \tilde{w}_{t}+v r_{t}}\right]=\frac{R \lambda_{t}^{t-1}+\varepsilon \tilde{w}_{t}+v r_{t}}{1+\varepsilon \tilde{w}_{t}+v r_{t}}
$$

where $R$ is the habits parameter $(0<R<1)$, while $\varepsilon$ and $v$ reflect the impact of $\tilde{w}_{t}$ and $r_{t}$ on $\lambda_{t+1}^{t}$. The model in Section 2 corresponds to the case where $R=1$, whereas $\varepsilon=v=0$. Here again, we shall suppose that economic expansion has a globally positive influence on $\lambda_{t+1}^{t}$, which can be written as $\varepsilon(1-\tau)+v \tau(1-\psi)>0$, where $\psi$ denotes the share of $r_{t}$ in the public budget.

The length of the second period is, under $\varepsilon, v>0$, affected positively by $\tilde{w}_{t}$ and $r_{t}$, but at a declining rate. Moreover, $\tilde{w}_{t}$ and $r_{t}$ are competing channels by which economic development can affect the maximum length of life: the influence of each of these is declining with the level of the other. One should also notice that habits have a positive influence on $\lambda_{t+1}^{t}$, but declining with $\tilde{w}_{t}$ and $r_{t}$, which is plausible.

Whereas the modelling of $\lambda_{t+1}^{t}$ looks like the one of $\phi_{t+1}^{t}$, the two processes at work are likely to differ significantly. Actually, habits may play a stronger role for $\lambda_{t+1}^{t}$ than for $\phi_{t+1}^{t}$. The reason for this is that, among the main causes of death for young adults, death by car accident and death by suicide are causes for which there can be little dependency on past achievements, so that $B$ is low (and probably lower than $R$ ). Public expenditures programs favouring security

its impact on, among other things, the climate, the quality of air and water, are - although measurable - not easily identifiable as the cause of mortality changes (see Sartor, 2002).

${ }^{17}$ See Wilmoth et al (2000) and Vallin and Berlinguer (2002).

${ }^{18} \mathrm{On}$ the influence of habits and customs on the mortality at high ages, see Vallin et al (2002). 
on roads must be re-spent every year, otherwise the number of accidents tends to rise again. Hence, habits parameters $B$ and $R$ are likely to differ significantly.

\subsection{Government}

The government implements now two kinds of policies: on the one hand, public expenditures $g_{t}$ affecting the proportion of survivors within a generation; on the other hand, "pure longevity" expenditures $r_{t}$, which raise the length of life enjoyed by survivors. Those expenditures can take various forms: medical research against ageing diseases, various preventive programs, etc.

The government's budget constraint is now:

$$
\tau w_{t}=g_{t}+r_{t}
$$

For convenience, we shall introduce the parameter $\psi(0 \leq \psi \leq 1)$, which is the share of the budget dedicated to policies affecting $\phi_{t+1}^{t}$, while the proportion $(1-\psi)$ of the budget is dedicated to expenditures $r_{t}$.

\subsection{Steady-states}

Within this extended model, the capital accumulation equation is:

$$
k_{t+1}=\frac{(1-\alpha)(1-\tau)}{1+n} A k_{t}^{\alpha} \frac{\beta \phi_{t}^{t-1} \lambda_{t}^{t-1}}{1+\beta \phi_{t}^{t-1} \lambda_{t}^{t-1}}
$$

The unique difference with respect to the basic model is that the length of the second period is no longer constant across generations.

As in the previous Section, fixing $k_{t+1}=k_{t}$ allows us to derive the $k k$ locus:

$$
k=\left(\frac{(1-\tau)(1-\alpha) A \beta \phi \lambda}{(1+n)(1+\beta \phi \lambda)}\right)^{\frac{1}{1-\alpha}}
$$

The $k k$ locus gives us, for each combination of $\phi$ and $\lambda$, the value of $k$ such that $k$ is constant. The length $\lambda$ is no longer fixed here, so that the $k k$ locus is not a curve in the $(\phi, k)$ space, but a plane in the $(\phi, k, \lambda)$ space.

The survival production function is now:

$$
\phi_{t+1}^{t}=\frac{B \phi_{t}^{t-1}+\gamma(1-\tau)(1-\alpha) A k_{t}^{\alpha}+\delta \tau \psi(1-\alpha) A k_{t}^{\alpha}}{1+\gamma(1-\tau)(1-\alpha) A k_{t}^{\alpha}+\delta \tau \psi(1-\alpha) A k_{t}^{\alpha}}
$$

Fixing $\phi_{t+1}^{t}=\phi_{t}^{t-1}$ allows us to derive the $\phi \phi$ locus:

$$
k=\left[\phi \frac{1-B}{A(1-\phi)(1-\alpha)(\gamma(1-\tau)+\delta \tau \psi)}\right]^{\frac{1}{\alpha}}
$$

We shall, as in Section 2, make the plausible postulate that the global impact of economic development on $\phi_{t+1}^{t}$ is strictly positive. ${ }^{19}$

\footnotetext{
${ }^{19}$ In the extended model, that assumption becomes $(\gamma(1-\tau)+\delta \tau \psi)>0$.
} 
Finally, fixing $\lambda_{t+1}^{t}=\lambda_{t}^{t-1}$ within the longevity production function:

$$
\lambda_{t+1}^{t}=\frac{R \lambda_{t}^{t-1}+\varepsilon(1-\tau)(1-\alpha) A k_{t}^{\alpha}+v \tau(1-\psi)(1-\alpha) A k_{t}^{\alpha}}{1+\varepsilon(1-\tau)(1-\alpha) A k_{t}^{\alpha}+v \tau(1-\psi)(1-\alpha) A k_{t}^{\alpha}}
$$

allows us to derive the $\lambda \lambda$ locus:

$$
k=\left[\lambda \frac{1-R}{A(1-\lambda)(1-\alpha)(\varepsilon(1-\tau)+v \tau(1-\psi))}\right]^{\frac{1}{\alpha}}
$$

We shall assume that the global impact of economic development on $\lambda_{t+1}^{t}$ is strictly positive. ${ }^{20}$

The question of the existence of an equilibrium, which could, in the basic model, be formulated as the search for an intersection of the $k k$ and $\phi \phi$ loci in the 2-dimensional space $(\phi, k)$, must now be reformulated as the question of the intersection of the loci $k k, \phi \phi$ and $\lambda \lambda$ in the 3 -dimensional space $(\phi, k, \lambda)$. In order to connect the present framework with the basic model, the three loci are, in Figure 5, represented as a collection of curves.

Actually, the basic model can be regarded as a particular case of the present one, where the selection of a specific value for $\lambda$ amounts to "choose", from the $k k$ plane shown in the first graph of Figure 5, a single curve among the ones constituting the $k k$ locus. In a similar way, a single curve was selected from the $\phi \phi$ plane (see the second graph). Having selected those curves, corresponding to the $k k$ and $\phi \phi$ loci for a specific $\lambda$, one could then discuss the possibility of their intersection.

Figure 5: The $k k, \phi \phi$ and $\lambda \lambda$ loci in the $(\phi, \lambda, k)$ space $(A=20, \alpha=0.5$, $\beta=0.99, \tau=0.25, \psi=0.5, B=0.5, \gamma=0.1, \delta=0.3, R=0.5, \varepsilon=0.1$, $v=0.3)$

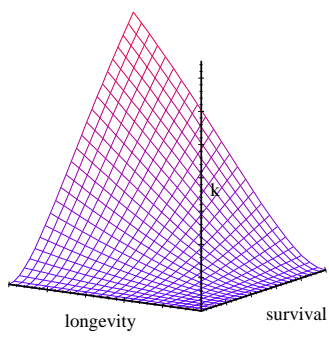

$k k$ locus

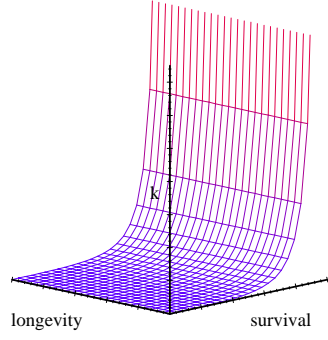

$\phi \phi$ locus

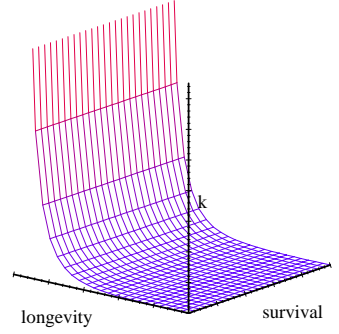

$\lambda \lambda$ locus

In order to discuss the existence issue in the present framework, one strategy consists of deriving the equations describing the intersection of the $k k$ locus with, on the one hand, the $\phi \phi$ locus, and, on the other hand, the $\lambda \lambda$ locus. Given that

\footnotetext{
${ }^{20}$ That assumption is $(\varepsilon(1-\tau)+v \tau(1-\psi))>0$.
} 
the first derived curve provides us, for different values of $\lambda$, the combinations of $k$ and $\phi$ such that $k$ and $\phi$ are constant, while the second curve provides us, for different values of $\phi$, the combinations of $k$ and $\lambda$ that are constant, an equilibrium would lie at the intersection of those two curves, because an equilibrium point must, by definition, belong to the three loci. To illustrate this strategy, Figure 6 puts on the same graph the three loci from Figure 5. Those loci intersect not only at the origin, but also at another point, which is a non-trivial equilibrium.

Figure 6: Existence of an equilibrium $(A=20, \alpha=0.5, \beta=0.99, \tau=0.25$, $\psi=0.5, B=0.5, \gamma=0.1, \delta=0.3, R=0.5, \varepsilon=0.1, v=0.3)$

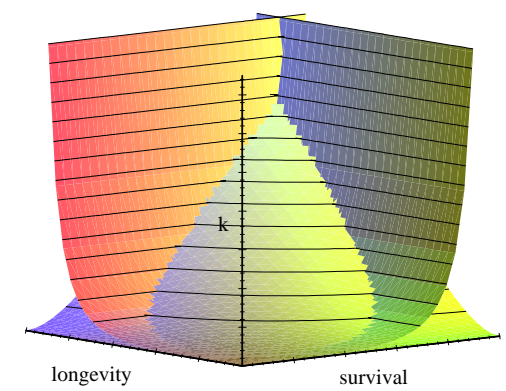

Regarding the conditions guaranteeing the existence of a non-trivial equilibrium, it is shown in the Appendix that, provided economic expansion has a globally positive influence on each aspect of longevity, the condition $\alpha<1 / 3$ guarantees the existence of a non-trivial steady-state. Moreover, that condition guarantees also the unicity of the non-trivial equilibrium.

However, if that condition is not satisfied (i.e. $\alpha \geq 1 / 3$ ), neither the existence nor the unicity of a non-trivial steady-state is guaranteed: one may have no nontrivial steady-state, or, alternatively, several non-trivial equilibria may exist.

Let us first consider a case of non-existence. For that purpose, let us, for instance, suppose that $\alpha$ is $0.4, \tau$ is 0.9 , while $\psi$ is 0.99 . Whereas Section 2 suggests that, under that calibration, a non-trivial equilibrium must exist under an exogenous $\lambda(\lambda>0)$, this is no longer true once $\lambda$ is endogenous. To see this, let us first present, on two distinct graphs, the intersections between, on the one hand, the $k k$ and $\phi \phi$ loci, and, on the other hand, between the $k k$ and $\lambda \lambda$ loci.

Figure 7: Non-existence of a non-trivial steady-state $(A=20, \alpha=0.4$, $\beta=0.99, \tau=0.9, \psi=0.99, B=0.5, \gamma=0.1, \delta=0.3, R=0.5, \varepsilon=0.1$, $v=0.3)$. 


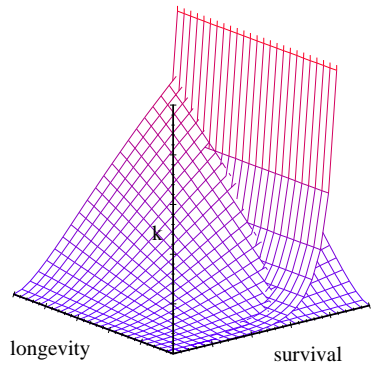

$k k$ locus and $\phi \phi$ locus

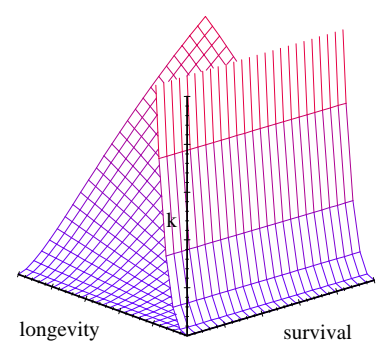

$k k$ locus and $\lambda \lambda$ locus

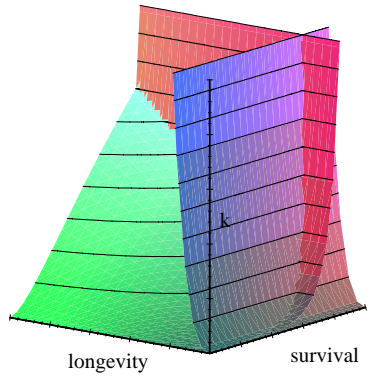

Non-existence

The left graph of Figure 7 illustrates clearly that, for a fixed, non-zero value of $\lambda$, there must exist a non-trivial equilibrium. Actually, as it was stressed above, fixing $\lambda$ amounts to select a single curve from the myriad of curves constituting the $k k$ locus, and, similarly, the single curve corresponding to the same value of $\lambda$ from the $\phi \phi$ locus. It is straightforward to see that, provided the selected $\lambda$ is strictly positive, the two selected curves - i.e. the $k k$ and $\phi \phi$ loci from the previous Section - necessarily intersect at a non-trivial equilibrium. Nonetheless, there exists no non-trivial equilibrium in the extended model, because the curve defined by the intersection of the $k k$ and $\lambda \lambda$ loci, which is illustrated on the second graph of Figure 7, only intersects the curve defined by the intersection of the $k k$ and $\phi \phi$ loci at the origin of axes. Therefore, there is no non-trivial intersection of the three loci, so that no non-trivial equilibrium exists.

While the above numerical example is extreme, it suffices to illustrate that, once $\lambda_{t+1}^{t}$ is endogenous, the existence of a non-trivial equilibrium is no longer guaranteed by the conditions stated in the basic model, so that stronger conditions are required. That stronger, sufficient condition is that $\alpha<1 / 3$, so that a less capital-intensive production process is required to guarantee the existence of a non-trivial equilibrium. The intuition behind that stronger condition is the following: once $\lambda_{t+1}^{t}$ is endogenous, the economy's take-off becomes more difficult, so that, in order to avoid stagnation, a less capital-intensive production process is required.

Regarding the unicity issue, it should be stressed that the extended model does not necessarily lead to a unique non-trivial equilibrium. Actually, the three loci may intersect at several points, as shown by Figure 8.

Figure 8: Multiple equilibria $(A=20, \alpha=0.7, \beta=0.99, \tau=0.25, \psi=0.5$, $B=0.5, \gamma=0.1, \delta=0.3, R=0.5, \varepsilon=0.1, v=0.3)$. 


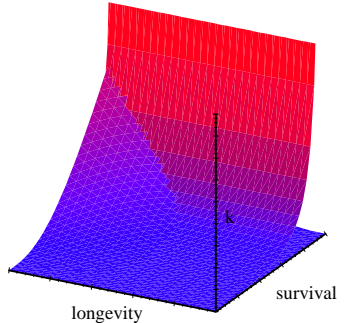

$k k$ locus and $\phi \phi$ locus

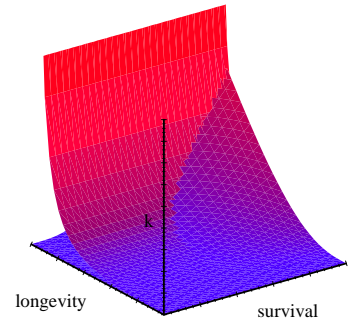

$k k$ locus and $\lambda \lambda$ locus

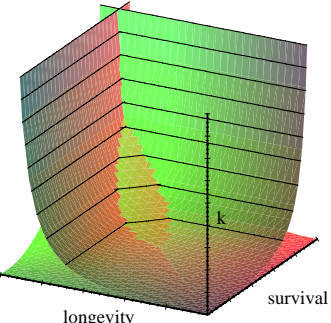

Multiple equilibria

Having discussed the existence and unicity of an equilibrium, we can now discuss briefly its stability. Given that the stability issue was studied in depth in the basic model, we shall confine ourselves here to an intuitive discussion in the light of phase diagrams. Let us suppose that a non-trivial equilibrium exists, as on Figure 6. To see why that equilibrium is likely to be stable, one can draw, as in the 2-dimensional case, the horizontal and vertical arrows describing the dynamics of the economy outside the three loci. Given that the vertical arrows are directed upwards below the $k k$ locus, and downwards above the $k k$ locus, and given that the directions pointed to by the horizontal arrows associated to the $\phi \phi$ and $\lambda \lambda$ loci, the non-trivial equilibrium, if it exists, is likely to be locally stable. A similar procedure can be used to show that, under multiple non-trivial equilibria, the intermediate equilibrium is locally unstable. However, it should be reminded that such a diagram-based analysis is only an intuitive way to discuss the stability: in cases where the non-trivial equilibrium is close to the origin of axes, its stability, even local, depends also on the stability of zero, so that a formal analysis is required.

\subsection{Comparative statics}

Let us now consider the impact of various parameters on the steady-state. Table 3 , which summarizes those effects, invites three remarks.

Firstly, the parameters $A, \beta$ and $n$, which affect the accumulation of capital directly, also influence the steady-state levels of $\phi$ and $\lambda$ in the same directions. This indirect influence follows from the postulated endogeneity of $\phi$ and $\lambda$ : when an economy accumulates more capital, this has here a positive influence on $\phi$ [provided $\gamma(1-\tau)+\delta \psi \tau>0$ ], and on $\lambda$ [provided $\varepsilon(1-\tau)+v(1-\psi) \tau>0$ ]. Therefore, any factor favouring capital accumulation also raises $\phi^{*}$ and $\lambda^{*}$.

Secondly, the parameters entering the survival production function - i.e. $\gamma, \delta$ and $B$ - do not only affect $\phi^{*}$ positively, but, also, via their positive effect on capital accumulation, $\lambda^{*}$. For instance, if public expenditures promoting security on roads become more productive in terms of $\phi$ (i.e. $\delta$ is raised), this will also raise $k^{*}$ and $\lambda^{*}$. This indirect influence comes from the savings decision: more security on roads increases the probability to live the second period, which makes individuals save more, which leads to a higher output, and, in fine, to a higher longevity. 
Table 3: Comparative statics results

\begin{tabular}{|cccc|}
\hline Parameter & Effect on $k^{*}$ & Effect on $\phi^{*}$ & Effect on $\lambda^{*}$ \\
$A$ & + & + & + \\
$\beta$ & + & + & + \\
$n$ & - & - & - \\
$B$ & + & + & + \\
$\gamma$ & + & + & + \\
$\delta$ & + & + & + \\
$R$ & + & + & + \\
$\varepsilon$ & + & + & + \\
$v$ & + & + & + \\
$\tau$ & $?$ & $?$ & $?$ \\
$\psi$ & $?$ & $?$ & $?$ \\
\hline
\end{tabular}

Thirdly, it should be stressed that, exactly as in the basic model, the influence of public policy parameters $\tau$ and $\psi$ on the steady-state is unknown.

The unknown impact of $\tau$ follows from the fact that taxation has, as in the basic framework, two opposite effects on capital accumulation: on the one hand, a higher $\tau$, by shrinking the share of the wage available for savings, tends to slowdown capital accumulation; on the other hand, if one supposes that governmental intervention brings some extra-value as far as survival conditions are concerned, a higher $\tau$ leads to a rise in $\phi$ and $\lambda$, which promotes capital accumulation. Hence, those opposite effects imply that the impact of raising $\tau$ on steady-state capital is unknown. But, given that $\phi$ and $\lambda$ are also influenced by the untaxed wage, the effect of $\tau$ on their levels is also unknown: a higher $\tau$ does not necessarily lead to a higher longevity.

Finally, one should notice that the impact of $\psi$ on the steady-state is unknown: in some cases, a higher proportion $\psi$ of the government's budget allocated to survival expenditures $g_{t}$ may affect the steady-state positively, whereas it may have, in other cases, a negative effect on not only $k^{*}$ and $\lambda^{*}$, but, also, on $\phi^{*}$. The reason why such a surprising result may occur is that changing $\psi$ amounts to move the $\phi \phi$ and $\lambda \lambda$ loci in opposite directions (while the $k k$ locus remains unchanged). Hence, given that the steady-state $\phi^{*}$ depends also on where the $\lambda \lambda$ locus lies, an optimal policy requires some kind of "balance" between the two kinds of public programs, balance whose precise form depends on the parameters determining $\phi$ and $\lambda$.

\subsection{Numerical application: the optimal long-run policy}

Let us now study, by means of a simple numerical application, the definition of the optimal allocation of the public budget between, on the one hand, spendings $g_{t}$, affecting the proportion of survivors $\phi_{t+1}^{t}$, and, on the other hand, expenditures $r_{t}$, which raise the maximum length of life $1+\lambda_{t+1}^{t}$. For that purpose (selecting the optimal $\psi$ ), we shall make two restrictions. 
Firstly, we shall focus on the optimal long-run public policy, i.e., the policy maximizing the steady-state utility of a representative agent. ${ }^{21}$ Such a focus on the steady-state is a simplification, because it ignores the welfare of all generations living before the steady-state is reached. However, given that the steadystate is, by definition, the state where the economy will remain forever once it has been reached, analyzing optimal public policy from that point of view is definitely relevant. ${ }^{22}$

Secondly, we shall examine the question of the optimal long-run $\psi$ for a given fiscal capacity, that is, for a fixed $\tau$. While this restriction is non-negligible, one should not exaggerate its strength: it is straightforward to imagine a situation where, because of political hysteresis, the fiscal pressure cannot be changed.

In order to study the optimal $\psi$, we shall proceed in two stages. In a first stage, we shall postulate that development is "neutral", in the sense that it affects $\phi_{t+1}^{t}$ and $\lambda_{t+1}^{t}$ in an identical manner. Then, we shall consider the more realistic - case where development is not neutral.

Under a neutral development, there are potentially two factors determining the optimal long-run $\psi$ : on the one hand, the "productivities" of the two kinds of public expenditures $g_{t}$ and $r_{t}$, and, on the other hand, the differences in the corresponding dependency on the past.

The crucial impact of the productivities on $\psi^{*}$ is illustrated by Table 4 , under the assumption of identical habits parameters $(B=R=0.5)$ and a neutral, but weakly positive, development $(\gamma=\varepsilon=0.05)$. When the productivities of the two public spendings are equal, then, given that the two production processes are exactly identical, the optimal $\psi$ is $50 \%{ }^{23}$ Nevertheless, this case is purely theoretical: raising $\phi_{t+1}^{t}$ or $\lambda_{t+1}^{t}$ is not equally difficult: the proportion of survivors of the first period is far easier to raise than maximum longevity.

As Table 4 illustrates, introducing some productivity gap does not leave $\psi^{*}$ unchanged. Reducing $v$ tends, ceteris paribus, to lead to a higher $\psi^{*}$, suggesting that it is desirable to spend more where the productivity is higher. However, one should notice that, even when the impact of $r_{t}$ on $\lambda_{t+1}^{t}$ becomes as low as the "natural" impact of economic development, it is still desirable to dedicate a significant part of the budget to $r_{t}$. The intuition behind that result goes as follows: given the postulated utility function, which treats $\phi_{t+1}^{t}$ and $\lambda_{t+1}^{t}$ in a symmetric way, some "balance" is always required between the resources dedicated to $\phi_{t+1}^{t}$ and to $\lambda_{t+1}^{t}$, because these are equally important for welfare.

\footnotetext{
${ }^{21}$ Given that the postulated parameters do not guarantee the uniqueness of a steady-state, it is important to stress that $\psi^{*}$ is here defined as the one maximizing the utility at the upper steady-state. Focussing on the upper steady-state amounts to suppose that this equilibrium can be reached given the initial conditions. However, the selected parameters always lead to an extremely low intermediate equilibrium, so that assuming that initial conditions are such that the poverty trap is avoided constitutes a weak postulate.

${ }^{22}$ One should also notice that focussing on the steady-state allows us to avoid the possibility of a difference between ex ante and ex post average lifetime utility (such a difference occurs outside the steady-state, because the actual values of $\lambda_{t+1}^{t}$ and $\phi_{t+1}^{t}$ differ from their expected values outside the steady-state).

${ }^{23}$ This result follows from the fact that $\phi_{t+1}^{t}$ and $\lambda_{t+1}^{t}$ are treated in the same way in the utility function of the representative agent, for whom life expectancy, equal to $1+\left(\phi_{t+1}^{t} \lambda_{t+1}^{t}\right)$, is the unique thing that matters from a demographic point of view.
} 
Table 4: Optimal $\psi(A=20, \alpha=0.5, \beta=0.99, \tau=0.25)$

\begin{tabular}{|ccccccc|}
\hline$\gamma$ & $\delta$ & $B$ & $\varepsilon$ & $v$ & $R$ & $\psi^{*}(\%)$ \\
0.05 & 0.3 & 0.5 & 0.05 & 0.3 & 0.5 & 50 \\
0.05 & 0.3 & 0.5 & 0.05 & 0.2 & 0.5 & 52 \\
0.05 & 0.3 & 0.5 & 0.05 & 0.1 & 0.5 & 65 \\
0.05 & 0.3 & 0.5 & 0.05 & 0.075 & 0.5 & 74 \\
0.05 & 0.3 & 0.5 & 0.05 & 0.05 & 0.5 & 91 \\
\hline
\end{tabular}

Whereas Table 4 emphasized that differences in the productivity of public policies affect $\psi^{*}$ under an equal dependence on the past for $\phi_{t+1}^{t}$ and $\lambda_{t+1}^{t}$, it should be stressed that the latter assumption is quite restrictive. Actually, as it was argued above, there exist good reasons to believe that the impact of the past is stronger in the determination of $\lambda_{t+1}^{t}$ than in the determination of $\phi_{t+1}^{t}$. For instance, the major causes of death for young adults - car accidents and suicides - can hardly be affected by past achievements, so that the influence of the past may, for $\phi_{t+1}^{t}$, be lower than for $\lambda_{t+1}^{t}$.

As one may expect, differences in the degree of dependence on the past can hardly leave $\psi^{*}$ unaffected. That intuition is confirmed by Table 5: once a differential in accumulation factors is introduced in favour of $\lambda_{t+1}^{t}$ with respect to $\phi_{t+1}^{t}, \psi^{*}$ becomes significantly higher. It is, for instance, as high as $71 \%$ under $B$ equal to 0.5 and $R$ equal to 0.6 , against only $65 \%$ under an identical dependence on the past (see Table 4). Not surprisingly, stronger differences in the degree of dependence on past achievements lead to higher $\psi^{*}$. But more surprising is that, under $R$ equal to $90 \%$, the optimal policy is to spend exclusively on $\phi_{t+1}^{t}$. This follows from the conjunction of the positive natural influence of development on $\lambda_{t+1}^{t}$ with strong customs, which makes public intervention unnecessary from a long-run perspective.

While it was supposed so far that economic development is neutral, in the sense that it affects $\phi_{t+1}^{t}$ and $\lambda_{t+1}^{t}$ in a similar manner, such a neutrality lacks empirical support. Actually, even though it is hard to separate the contributions of each - private and public - factor on longevity, the "natural" influence of economic development on $\phi_{t+1}^{t}$ is likely to have been significantly stronger than its influence on $\lambda_{t+1}^{t}$, as suggested by the historical fact that, at periods of limited public intervention, longevity progress began with a strong fall in mortality at low ages, before affecting mortality at all ages. ${ }^{24}$

As illustrated by Table 6 , introducing an asymmetry in the natural impact of development on $\phi_{t+1}^{t}$ and $\lambda_{t+1}^{t}$ is not without consequences on $\psi^{*} .^{25}$ If, for instance, one reduces $\varepsilon$ from 0.05 to 0.04 , everything else remaining unchanged with respect to Table $4, \psi^{*}$ falls from $65 \%$ to $54 \%$. Reducing $\varepsilon$ further tends to lead to even lower values of $\psi^{*}$. The tendency of $\psi^{*}$ towards 0 when $\varepsilon$ tends to 0 is not surprising: once the natural impact of prosperity on the maximum

\footnotetext{
${ }^{24}$ See Vallin and Berlinguer (2002).

${ }^{25}$ For the convenience of the presentation, $B$ and $R$ are now equal as in Table 4 .
} 
length of life becomes very small, public intervention becomes the unique way to improve $\lambda_{t+1}^{t}$, so that the optimal budget is strongly unbalanced in favour of the aspect of longevity that cannot be improved without public intervention.

Table 5: Optimal $\psi(A=20, \alpha=0.5, \beta=0.99, \tau=0.25)$

\begin{tabular}{|ccccccc|}
\hline$\gamma$ & $\delta$ & $B$ & $\varepsilon$ & $v$ & $R$ & $\psi^{*}(\%)$ \\
0.05 & 0.3 & 0.5 & 0.05 & 0.1 & 0.6 & 71 \\
0.05 & 0.3 & 0.5 & 0.05 & 0.1 & 0.7 & 80 \\
0.05 & 0.3 & 0.4 & 0.05 & 0.1 & 0.7 & 86 \\
0.05 & 0.3 & 0.5 & 0.05 & 0.1 & 0.8 & 94 \\
0.05 & 0.3 & 0.5 & 0.05 & 0.1 & 0.9 & 100 \\
\hline
\end{tabular}

Hence, Table 6 suggests that, even though some public policies may be more efficient than others, what is crucial, at the end of the day, for the determination of $\psi^{*}$, is the precise extent by which each longevity aspect can grow without governmental intervention. If one has good reasons to believe that the length of the second period $\lambda_{t+1}^{t}$ is likely to be less easily raised, without public intervention, than the proportion of survivors $\phi_{t+1}^{t}$, this justifies, from a long-run perspective, a larger share of the budget to be spent on policies raising $\lambda_{t+1}^{t}$, even if the productivity of such policies is lower. Thus, all this tends to cast some doubts on the $\psi^{*}$ derived under neutral economic development (Table 4).

Table 6: Optimal $\psi(A=20, \alpha=0.5, \beta=0.99, \tau=0.25)$

\begin{tabular}{|ccccccc|}
\hline$\gamma$ & $\delta$ & $B$ & $\varepsilon$ & $v$ & $R$ & $\psi^{*}(\%)$ \\
0.05 & 0.3 & 0.5 & 0.04 & 0.1 & 0.5 & 54 \\
0.05 & 0.3 & 0.5 & 0.03 & 0.1 & 0.5 & 43 \\
0.05 & 0.3 & 0.5 & 0.02 & 0.1 & 0.5 & 32 \\
0.05 & 0.3 & 0.5 & 0.01 & 0.1 & 0.5 & 22 \\
0.05 & 0.3 & 0.5 & 0.005 & 0.1 & 0.5 & 17 \\
\hline
\end{tabular}

Having studied the impact of a non-neutral development, we can now reintroduce differences in past-dependency, in order to examine the optimal policy once the major differences between the production of $\phi_{t+1}^{t}$ and $\lambda_{t+1}^{t}$ are taken into account.

As Table 7 confirms, introducing differences in the degree of dependence on past longevity achievements affects $\psi^{*}$ significantly. For instance, under $\varepsilon$ equal to 0.03 , a rise in $R$ from 0.5 to 0.7 raises $\psi^{*}$ from $43 \%$ à $54 \%$. Moreover, under 
$\varepsilon$ equal to 0.01 , raising $R$ from 0.5 to 0.8 makes $\psi^{*}$ grow from $22 \%$ to $29 \%$. However, Table 7 suggests that the mere existence of a stronger dependence on the past for $\lambda_{t+1}^{t}$ does not suffice, in itself, to justify an "unbalanced" budget structure favouring expenditures of kind $g_{t}$ over expenditures of type $r_{t}$.

Table 7: Optimal $\psi(A=20, \alpha=0.5, \beta=0.99, \tau=0.25)$

\begin{tabular}{|ccccccc|}
\hline$\gamma$ & $\delta$ & $B$ & $\varepsilon$ & $v$ & $R$ & $\psi^{*}(\%)$ \\
0.05 & 0.3 & 0.5 & 0.03 & 0.1 & 0.7 & 54 \\
0.05 & 0.3 & 0.5 & 0.01 & 0.1 & 0.7 & 29 \\
0.05 & 0.3 & 0.5 & 0.01 & 0.1 & 0.8 & 36 \\
0.05 & 0.3 & 0.3 & 0.01 & 0.1 & 0.8 & 43 \\
0.05 & 0.3 & 0.1 & 0.01 & 0.1 & 0.8 & 47 \\
\hline
\end{tabular}

As shown by the last line of Table 7, even if one postulates that the pastdependency is, for $\lambda_{t+1}^{t}, 8$ times as strong as for $\phi_{t+1}^{t}$, the optimal allocation of public budget is still close to 50-50. Although this result is obtained under a significant difference in the natural impact of prosperity on $\phi_{t+1}^{t}$ and $\lambda_{t+1}^{t}$, smaller differences could not, however, suffice to justify extremely unbalanced budget structures.

Hence, this numerical exercise tends to question the optimality, from a longrun perspective, of strongly unbalanced public budgets favouring expenditures oriented towards the proportion of survivors over expenditures enhancing the maximum length of life. If one concentrates on the steady-state, it is hard to see how an extremely unbalanced budget could be justified. Given that, under the postulated additive expected lifetime utility, $\phi_{t+1}^{t}$ and $\lambda_{t+1}^{t}$ matter equally for the welfare of the representative agent, the competing effects at work suggest that the optimal budget structure should be, at least to some extent, balanced.

\section{Conclusions}

The aim of this paper was to examine the definition of the optimal long-run public intervention in a two-period OLG model where the proportion of survivors of the first period and the length of the second period can be affected by distinct public policies. For that purpose, we proceeded in two stages.

The presentation of the basic model - where the maximum length of life is fixed - allowed us to discuss the question of the optimal size of public intervention. As one may expect, the model suggests that, from a long-run perspective, there exists an optimal size of the State, which depends on the extra-value brought by public expenditures as far as the improvement of survival conditions is concerned. It may be the case that the natural impact of economic expansion 
on survival conditions is so positive that laissez-faire is optimal. However, if development affects survival conditions negatively, a much larger public intervention is justified.

The extended model, where the maximum length of life is endogenous, allowed us to examine the optimal structure of public intervention. The optimal allocation of public resources - for a fixed fiscal pressure - was shown to depend on the productivities of the different policies, on the "natural" impact of economic development on these, and, also, on the degree of dependence on past achievements. It was argued that those different determinants play in opposite directions, so that, given the equal importance, in welfare terms, of the proportion of survivors and the maximum longevity, the optimal public budget should be relatively "balanced" between survival-enhancing policies and programs raising the maximum age at death. Actually, whereas the latter kind of spendings may be less productive than the former, and habits mechanisms probably stronger for the maximum length of life, those two considerations, which support a larger budget share dedicated to survival-enhancing expenditures, are - at least partly - counter-balanced by the fact that the natural influence of economic expansion on mortality at lower ages is generally larger than on mortality at higher ages, which justifies some balance in the budget.

Finally, it cannot be overemphasized here that this paper is only a first step in the study of the optimal public policy under endogenous longevity. Actually, the present study focussed on the long-run, and, thus, excluded all generations living before the steady-state is reached. Given that the well-being of people living in the transition is also worth being taken into account, and given that the transition may be quite long, it would be interesting to include generations living during the transition, and to discuss the sensitivity of the optimal public intervention to the postulated concept of intergenerational justice.

Moreover, while this study emphasized that the optimal long-run policy depends on how economic development affects mortality, it should be stressed that other factors may also influence the optimal public intervention. Among other things, the precise form of individual preferences may also play a crucial role. Whereas we postulated a utility function where $\phi$ and $\lambda$ are treated in a symmetric way, such an assumption may be unrealistic: individuals may exhibit what Bommier (2003) calls "net" risk-aversion with respect to the length of life. Such an attitude, by implying a different weighting of $\phi$ and $\lambda$, may affect the structure of the optimal intervention. The optimal policy is also likely to be significantly sensitive to the postulated social welfare function (which was here the standard average view), and, especially, to the associated concerns for intragenerational inequality and numbers. Another factor that may influence the optimal public intervention consists of institutions, such as pensions schemes (see Pestieau et al, 2006). Hence, much work remains to be done in the future. 


\section{R eferences}

Aisa, R. \& Pueyo, F. (2004): "Endogenous longevity, health and economic growth: a slow growth for a longer life?", Economics Bulletin, 9 (3), pp. 1-10.

Anand, S. \& Ravallion, M. (1993): "Human development in poor countries: on the role of private income and public services", Journal of Economic Perspectives, 7 (Winter), pp. $133-150$.

Bhattacharya, J. \& Qiao, X. (2005): "Public and private expenditures on health in a growth model", Iowa State University Working Paper, \#05020.

Bommier, A. (2003): "Risk aversion, intertemporal elasticity of substitution and correlation aversion", LEA Working Paper, \# 0307.

Boucekkine, R., de la Croix, D. \& Licandro, O. (2002) : "Vintage human capital, demographic trends, and endogenous growth", Journal of Economic Theory, 104, pp. 340-375.

Chakraborty, S. (2004): "Endogenous lifetime and economic growth", Journal of Economic Theory, 116, pp. 119-137.

de la Croix, D. \& Licandro, O. (1999) : "Life expectancy and endogenous growth", Economics Letters, 65, pp. 255-263.

Dreze, J. \& Sen, A.K. (1989): Hunger and Public Action, WIDER Studies in Development Economics. Oxford: Clarendon Press.

Easterlin, R. (1999): "How benevolent is the market? A look at the modern history of mortality", European Review of Economic History, 3, pp. 257-294.

Ehrlich, I. \& Lui, F.T. (1991): "Intergenerational trade, longevity, and economic growth", Journal of Political Economy, 99, pp. 1029-1060.

Finlay, J. (2005): "Endogenous longevity and economic growth", mimeographed, Australian National University.

Lichtenberg, F.R. (2002): "Sources of U.S. longevity increase, 1960-1997”, NBER Working Paper $\mathrm{n}^{\circ} 8755$.

Medio, A. \& Lines, M. (2001): Nonlinear Dynamics. A Primer. Cambridge: Cambridge University Press.

Nusselder, W.J. \& Mackenbach, J.P. (1996): "Rectangularization of survival curve in the Netherlands, 1950-1992", Gerontologist, 36, 6, pp. 773-781.

Pecchenino, R.A. \& Utendorf, K.R. (1999): "Social security, social welfare and the aging population", Journal of Population Economics, 12, 4, pp. 607-623.

Pestieau, P., Ponthiere, G. \& Sato, M. (2006) : "Longevity and pay-as-you-go pensions", CORE Discussion Paper 54.

Preston, S.H. (1975): "The changing relation between mortality and level of economic development", Population Studies, 29, 2, pp. 231-248.

Preston, S.H. (1980): "Causes and consequences of mortality declines in less developed countries during the twentieth century", in R.A. Easterlin (ed.): Population and Economic Changes in Developing Countries. Chicago: Chicago Press.

Pritchett, L. \& Summers, L.H. (1996): "Wealthier is healthier", Journal of Human Resources, 31, 4, pp. 841-868.

Sartor, F. (2002) : "Les facteurs environnementaux de la mortalité", in G. Caselli, J. Vallin \& G. Wunsch (eds.) Démographie : analyse et synthèse, volume III : Les déterminants de la mortalité. Paris: Editions de l'Institut National d'Etudes Démographiques. 
Soliani, L. \& Lucchetti, E. (2002) : "Les facteurs de la mortalité", in G. Caselli, J. Vallin \& G. Wunsch (eds.) Démographie : analyse et synthèse, volume III : Les déterminants de la mortalité. Paris: Editions de l'Institut National d'Etudes Démographiques.

Valkonen, T. (2002): "Les inégalités sociales devant la mort", in Caselli, G., Vallin, J. \& Wunsch, G. (eds.) Démographie : analyse et synthèse, volume III: Les déterminants de la mortalité. Paris: Editions de l'Institut National d'Etudes Démographiques.

Vallin, J. \& Berlinguer, G. (2002): "De la mortalité endogène aux limites de la vie humaine", in G. Caselli, J. Vallin \& G. Wunsch (eds.) Démographie : analyse et synthèse, volume III. Paris: Editions de l'Institut National d'Etudes Démographiques.

Vallin, J., Caselli, G. \& Surault, P. (2002) : "Comportements, styles de vie et facteurs socioculturels de la mortalité", in G. Caselli, J. Vallin \& G. Wunsch (eds.) Démographie : analyse et synthèse, volume III. Paris: Editions de l'Institut National d'Etudes Démographiques.

Wilmoth, J.R. \& Horiuchi, S. (1999): "Rectangularization revisited: variability of age at death within human populations", Demography, 36, 4, pp. 475-495.

Wilmoth, J.R., Deegan, L., Lundstrom, H. \&Horiuchi, S. (2000): "Increase in the maximum life-span in Sweden, 1861-1999", Science, 289, 29 (september), pp. 2366-2368.

Zhang, J., Zhang, J. \& Lee, R. (2001): "Mortality decline and long-run economic growth", Journal of Public Economics, 80, pp. 485-507.

\section{A ppendix}

\subsection{A ppendix A : Existence of steady-states in the basic model}

Let us first rewrite the $\phi \phi$ locus as:

$$
\phi=\frac{E k^{\alpha}}{E k^{\alpha}+(1-B)}
$$

where $E \equiv A(1-\alpha)((1-\tau) \gamma+\tau \delta)$. Given our assumptions $(A>0,0<\alpha<1$ and $(1-\tau) \gamma+\tau \delta>0), E$ is strictly positive.

Substituting for $k$ while using the $k k$ locus allows us to rewrite the above expression as:

$$
\phi=\frac{E\left[\frac{C \beta \lambda \phi}{(1+n)(1+\beta \lambda \phi)}\right]^{\frac{\alpha}{1-\alpha}}}{E\left[\frac{C \beta \lambda \phi}{(1+n)(1+\beta \lambda \phi)}\right]^{\frac{\alpha}{1-\alpha}}+(1-B)}
$$

Let us now denote the right-hand side of the above expression by $G(\phi)$. Proving the existence of an equilibrium amounts to find a fixed point of $G(\phi)$, that is, a value of $\phi$ such that $G(\phi)=\phi$. It is clear that 0 is such a fixed point. But we would like to show that, provided $\alpha<1 / 2$, at least one other fixed point 
- corresponding to a non-trivial equilibrium - must exist. For that purpose, we shall show that the function $G(\phi)$ satisfies the following properties: ${ }^{26}$

(i) $G(0)=0$

(ii) $G^{\prime}(\phi) \geq 0 \forall \phi \in[0,1]$

(iii) $\lim _{\phi \rightarrow 1} G(\phi) / \phi<1$

(iv) $\lim _{\phi \rightarrow 0} G^{\prime}(\phi)=+\infty$ if $\alpha<1 / 2$

Proof:

(i)

$$
G(0)=\frac{0}{0+(1-B)}=0
$$

(ii)

$G^{\prime}(\phi)=$
$\frac{C \beta \lambda \alpha\left[\frac{C \beta \lambda \phi}{(1+n)(1+\beta \lambda \phi)}\right]^{-1+\alpha}(1-B)}{E(1+n)(1+\beta \lambda \phi)^{2}(1-\alpha)\left[-\frac{1}{E}\left(-E-\left[\frac{C \beta \lambda \phi}{(1+n)(1+\beta \lambda \phi)}\right]^{-\alpha}+\frac{\alpha}{1+\alpha}+B\left[\frac{C \beta \lambda \phi}{(1+n)(1+\beta \lambda \phi)}\right]^{-\frac{\alpha}{1+\alpha}}\right)\right]^{2}} \geq 0$

(iii)

$$
\begin{gathered}
\lim _{\phi \rightarrow 1} G(\phi) / \phi= \\
\lim _{\phi \rightarrow 1}\left(\frac{E\left[\frac{C \beta \lambda \phi}{(1+n)(1+\beta \lambda \phi)}\right]^{\frac{\alpha}{1-\alpha}}}{\phi E\left[\frac{C \beta \lambda \phi}{(1+\alpha)(1+\beta \lambda \phi)}\right]^{1-\alpha}+\phi(1-B)}\right)= \\
\frac{E\left[\frac{C \beta \lambda}{(1+n)(1+\beta \lambda)}\right]^{\frac{\alpha}{1-\alpha}}}{E\left[\frac{C \beta \lambda}{(1+n)(1+\beta \lambda)}\right]^{1-\alpha}+(1-B)}<1
\end{gathered}
$$

(iv)

$$
\begin{gathered}
G^{\prime}(\phi)=\frac{d}{d \phi}\left[\left(1+\frac{(1-B)}{E\left[\frac{C \beta \lambda \phi}{(1+n)(1+\beta \lambda \phi)}\right]^{\frac{\alpha}{1-\alpha}}}\right)^{-1}\right] \\
=E\left[\frac{C \beta \lambda \phi}{(1+n)(1+\beta \lambda \phi)}\right]^{\frac{2 \alpha-1}{1-\alpha}} \frac{\left(\frac{C \beta \lambda}{(1+n)(1+\beta \lambda \phi)^{2}}\right)(1-B) \alpha}{(1-\alpha)\left(-E\left[\frac{C \beta \lambda}{(1+n)(1+\beta \lambda \phi)}\right]^{\frac{\alpha}{1-\alpha}}-1+B\right)^{2}}
\end{gathered}
$$

Hence,

$$
\begin{aligned}
\lim _{\phi \rightarrow 0} G^{\prime}(\phi) & =E\left[C \beta \lambda \frac{0}{(1+n)(1)}\right]^{\frac{2 \alpha-1}{1-\alpha}}(1-B) \alpha \frac{C \beta \frac{\lambda}{(1+n)(1)^{2}}}{(1-\alpha)(-1+B)^{2}} \\
& =+\infty \text { iff } \alpha<1 / 2
\end{aligned}
$$

\footnotetext{
${ }^{26}$ This part of the proof follows a method proposed by Chakraborty (2004).
} 
One can now see that, provided $\alpha<1 / 2, \lim _{\phi \rightarrow 0} G^{\prime}(\phi)$ is infinite, so that, given (i), (ii) and (iii), the function $G(\phi)$ must intersect the $45^{\circ}$ line at least once on the $[0,1]$ interval. Hence, in that case, at least one non-trivial equilibrium must exist. Figure 10 makes appear the crucial role played by condition (iv), which insures us that $G(\phi)$ must be above the $45^{\circ}$ line in the neighbourhhood of 0 , so that, given that $G(1)<1$, it is clear that a fixed point must exist.

Figure 10: Fixed-point under $\alpha<1 / 2(A=20, \tau=0.1, \beta=0.99, \lambda=0.8$, $n=0, \gamma=0.1, \delta=0.3$ and $B=0.5$ )

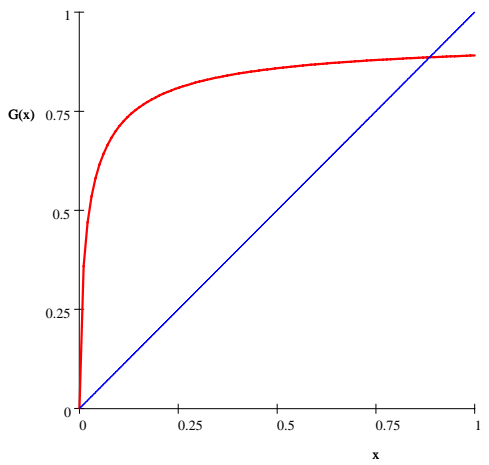

Case 1: $\alpha=0.4$

Moreover, in the light of the expression of $G^{\prime}(\phi)$, it is also possible to claim with certainty that such a non-trivial equilibrium must be unique. Indeed, it is straightforward to see that, provided $\alpha<1 / 2$, increasing $\phi$ implies a decrease of the first factor of $G^{\prime}(\phi)$. Moreover, the numerator of the second factor of $G^{\prime}(\phi)$ decreases when $\phi$ increases, while its denominator increases, so that the second factor must also necessarily fall when $\phi$ increases. Hence, one can conclude from this that $G^{\prime}(\phi)$ is, under $\alpha<1 / 2$, decreasing with $\phi$, so that the nontrivial equilibrium is, in that case, unique.

However, if $\alpha \geq 1 / 2$, the $\lim _{\phi \rightarrow 0} G^{\prime}(\phi)=0$, so that it is not clear whether a non-trivial equilibrium exists or not. Three sub-cases should be distinguished. These are illustrated on Figure 13.

On the one hand, if the $G(\phi)$ curve lies slightly above the $45^{\circ}$ line in the neighbourhood of zero, we know that there must exist a non-trivial equilibrium, because $G(\phi)$ tends to a value strictly lower than unity when $\phi$ tends to 1 , so that the $G(\phi)$ curve must necessarily, in that case, intersect the $45^{\circ}$ line on the $[0,1]$ interval.

On the other hand, if the $G(\phi)$ curve lies below the $45^{\circ}$ line in the neighbourhood of zero, it is not clear whether a non-trivial equilibrium exists: two sub-cases should be distinguished. Firstly, it may be the case that the $G(\phi)$ curve intersects the $45^{\circ}$ line once from below, and then a second time from above (which must be the case here, because $G(1)<1$ ). This case is possible, 
because, as we saw above, under $\alpha \geq 1 / 2$, the $G(\phi)$ curve is not necessarily concave over the entire interval. Secondly, it is also possible that the $G(\phi)$ curve remains below the $45^{\circ}$ line over the entire $[0,1]$ interval, so that no non-trivial equilibrium exists.

Figure 11: Fixed-points under $\alpha \geq 1 / 2(A=20, \tau=0.1, \beta=0.99, \lambda=0.8$, $n=0, \gamma=0.1, \delta=0.3$ and $B=0.5$ )

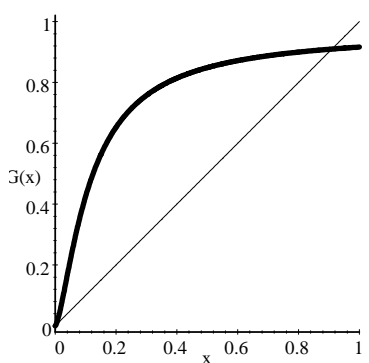

Case 2a: $\alpha=0.6$

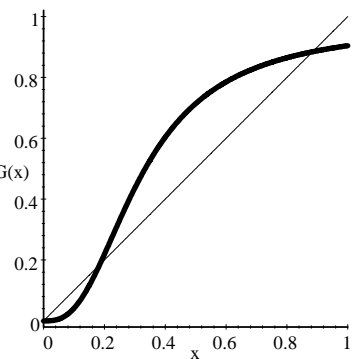

Case 2b: $\alpha=0.75$

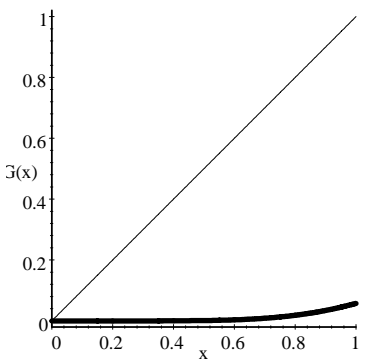

Case 2c: $\alpha=0.9$

\subsection{A ppendix B: Stability of steady-states in the basic model}

While the discussion of the stability of equilibria carried out in Section 2 in the light of phase diagrams suggested that non-trivial equilibria are likely to be stable (except the intermediate equilibrium), a more formal study of the stability is nonetheless required, because phase diagrams can sometimes simplify the picture significantly.

To discuss the stability of equilibria, let us first notice that the present system is non-linear, so that the conventional analysis of the Jacobian matrix (composed of the first-order derivatives of dynamic equations with respect to state variables) can only inform us on the stability of equilibria provided these are hyperbolic. Actually, if a fixed-point is hyperbolic, the Hartman-Grobman Theorem states that the stability of the linearized system (or its non-stability) implies the local stability of the non-linear system (or its non-stability) (see Medio and Lines, 2001). However, if the fixed-point is not hyperbolic, then the analysis of the linearized system does not allow us to draw any conclusion on the local stability of the non-linear system.

As stated in Medio and Lines (2001), fixed-points are, in discrete-time systems, hyperbolic if none of the eigenvalues of the Jacobian matrix, evaluated at the equilibrium, is equal to 1 in modulo.

To discuss the hyperbolicity of non-trivial equilibria, let us first compute the Jacobian matrix associated with the basic model of Section 2: 


$$
J \equiv\left(\begin{array}{cc}
\frac{\partial M\left(k_{t}, \phi_{t}^{t-1}\right)}{\partial k_{t}} & \frac{\partial M\left(k_{t}, \phi_{t}^{t-1}\right)}{\partial \phi_{t}^{t-1}} \\
\frac{\partial N\left(k_{t}, \phi_{t}^{t-1}\right)}{\partial k_{t}} & \frac{\partial N\left(k_{t}, \phi_{t}^{t-1}\right)}{\partial \phi_{t}^{t-1}}
\end{array}\right)
$$

where $M\left(k_{t}, \phi_{t}^{t-1}\right)$ and $N\left(k_{t}, \phi_{t}^{t-1}\right)$ denote:

$$
\begin{gathered}
M\left(k_{t}, \phi_{t}^{t-1}\right) \equiv \frac{(1-\alpha)(1-\tau)}{1+n} A k_{t}^{\alpha} \frac{\beta \lambda \phi_{t}^{t-1}}{1+\beta \lambda \phi_{t}^{t-1}} \\
N\left(k_{t}, \phi_{t}^{t-1}\right) \equiv \frac{B \phi_{t}^{t-1}+(1-\alpha) A k_{t}^{\alpha}(\gamma(1-\tau)+\delta \tau)}{1+(1-\alpha) A k_{t}^{\alpha}(\gamma(1-\tau)+\delta \tau)}
\end{gathered}
$$

The relevant first-order derivatives are:

$$
\begin{gathered}
\frac{\partial M\left(k_{t}, \phi_{t}^{t-1}\right)}{\partial k_{t}}=(1-\alpha)(1-\tau) A k_{t}^{\alpha-1} \alpha \beta \lambda \frac{\phi_{t}^{t-1}}{(1+n)\left(1+\beta \lambda \phi_{t}^{t-1}\right)}>0 \\
\frac{\partial M\left(k_{t}, \phi_{t}^{t-1}\right)}{\partial \phi_{t}^{t-1}}=(1-\alpha)(1-\tau) A k_{t}^{\alpha} \beta \frac{\lambda}{(1+n)\left(1+\beta \lambda \phi_{t}^{t-1}\right)^{2}}>0 \\
\frac{\partial N\left(k_{t}, \phi_{t}^{t-1}\right)}{\partial k_{t}}=\frac{(1-\alpha) A \alpha((1-\tau) \gamma+\delta \tau) k_{t}^{\alpha}(1-B \phi)}{k_{t}\left(-1-A k_{t}^{\alpha}((1-\tau) \gamma+\delta \tau)(1-\alpha)\right)^{2}}>0 \\
\frac{\partial N\left(k_{t}, \phi_{t}^{t-1}\right)}{\partial \phi_{t}^{t-1}}=\left[\frac{B}{1+A k_{t}^{\alpha}((1-\tau) \gamma+\delta \tau)(1-\alpha)}\right]>0
\end{gathered}
$$

An equilibrium is hyperbolic if no eigenvalue of the Jacobian matrix, evaluated at the equilibrium, is equal to 1 in modulo. A sufficient condition for this hyperbolicity condition is that the trace of the Jacobian matrix (i.e. the sum of eigenvalues) is positive but strictly lower than 1 , and that the determinant of the Jacobian matrix (i.e. the product of eigenvalues) is positive but strictly lower than one.

Actually, it is easy to see that those conditions are also sufficient conditions for the local stability of the equilibrium, which requires that all eigenvalues of the Jacobian matrix are strictly lower than 1 in modulo.

These two conditions imply that, at the equilibrium $\left(k^{*}, \phi^{*}\right)$ : 


$$
\begin{gathered}
0<(1-\alpha)(1-\tau) A k^{* \alpha-1} \alpha \beta \lambda \frac{\phi^{*}}{(1+n)\left(1+\beta \lambda \phi^{*}\right)}+\left[\frac{B}{1+A k^{* \alpha}(\gamma(1-\tau)+\delta \tau)(1-\alpha)}\right]<1 \\
\text { and } \\
0<\left[\frac{(1-\alpha)(1-\tau) A k^{* \alpha-1} \alpha \beta \lambda \phi^{*} B}{(1+n)\left(1+\beta \lambda \phi^{*}\right)\left[1+A k^{* \alpha}(\gamma(1-\tau)+\delta \tau)(1-\alpha)\right]}\right]- \\
{\left[\frac{(1-\alpha)(\gamma(1-\tau)+\delta \tau) \alpha A k^{* \alpha}\left(1-B \phi^{*}\right)(1-\alpha)(1-\tau) A k^{* \alpha} \beta \lambda}{k^{*}\left(-1-A k^{* \alpha}(\gamma(1-\tau)+\delta \tau)(1-\alpha)\right)^{2}(1+n)\left(1+\beta \lambda \phi^{*}\right)^{2}}\right]<1(* *)}
\end{gathered}
$$

Regarding condition $\left(^{*}\right)$, the positivity of the sum in question is obvious. Hence $(*)$ can be reformulated as:

$$
(1-\alpha)(1-\tau) A k^{* \alpha-1} \alpha \beta \lambda \frac{\phi^{*}}{(1+n)\left(1+\beta \lambda \phi^{*}\right)}<1-\frac{B}{1+A k^{* \alpha}(\gamma(1-\tau)+\delta \tau)(1-\alpha)}
$$

which is likely to be satisfied when the equilibrium is reached at a high level of capital.

Regarding $(* *)$, the positivity constraint can be rewritten as:

$$
\begin{aligned}
& {\left[\frac{(1-\alpha)(1-\tau) A k^{* \alpha-1} \alpha \beta \lambda \phi^{*}}{(1+n)\left(1+\beta \lambda \phi^{*}\right)} \frac{B}{1+A k^{* \alpha}(\gamma(1-\tau)+\delta \tau)(1-\alpha)}\right]>} \\
& {\left[\frac{(1-\alpha)(\gamma(1-\tau)+\delta \tau) \alpha A k^{* \alpha}\left(1-B \phi^{*}\right)}{k^{*}\left(-1-A k^{* \alpha}(\gamma(1-\tau)+\delta \tau)(1-\alpha)\right)^{2}} \frac{(1-\alpha)(1-\tau) A k^{* \alpha} \beta \lambda}{(1+n)\left(1+\beta \lambda \phi^{*}\right)^{2}}\right]}
\end{aligned}
$$

or, in short,

$$
B \phi^{*}>\left[\frac{A k^{* \alpha}(\gamma(1-\tau)+\delta \tau)(1-\alpha)}{\left(1+A k^{* \alpha}(\gamma(1-\tau)+\delta \tau)(1-\alpha)\right)} \frac{\left(1-B \phi^{*}\right)}{\left(1+\beta \lambda \phi^{*}\right)}\right]
$$

which is, here again, a plausible condition if the equilibrium considered is characterized by sufficiently high $\phi$. Actually, given that the two factors on the right-hand side are smaller than unity, the above condition is likely to be satisfied provided $B$ is sufficiently large.

Regarding the second part of condition $(* *)$, it implies that:

$$
\begin{aligned}
& (1-\alpha)(1-\tau) A k^{* \alpha-1} \alpha \beta \lambda \phi^{*} B< \\
& \frac{k^{*}\left(1+A k^{* \alpha}(\gamma(1-\tau)+\delta \tau)(1-\alpha)\right)^{2}(1+n)\left(1+\beta \lambda \phi^{*}\right)^{2}+(1-\alpha)^{2}(\gamma(1-\tau)+\delta \tau)(1-\tau) \alpha A^{2} k^{* 2 \alpha}\left(1-B \phi^{*}\right) \beta \lambda}{k^{*}\left(1+A k^{* \alpha}(\gamma(1-\tau)+\delta \tau)(1-\alpha)\right)\left(1+\beta \lambda \phi^{*}\right)}
\end{aligned}
$$

Given that all factors on the left-hand side are - except $A$ - smaller than 1 by hypothesis, and that the right-hand side is clearly higher than 1 , this condition is likely to be satisfied, especially when $k^{*}$ is high.

To conclude, the present discussion of the stability of the equilibrium suggests that this stability cannot be fully guaranteed in all cases. However, as it was shown, the equilibrium is likely to be stable when it corresponds to a sufficiently high combination of $k^{*}$ and $\phi^{*}$. The reason for this is simple: being distant from the other equilibrium - i.e. the $(0,0)$ point - insures stability, whereas an equilibrium that is close to the $(0,0)$ is likely to be unstable. 


\subsection{A ppendix C: Existence of steady-states in the extended model}

In order to derive the conditions guaranteeing the existence of a non-trivial steady-state, we shall follow here the technique used in Appendix A.

Actually, one can rewrite the $\phi \phi$ locus as:

$$
\phi=\frac{k^{\alpha} V}{k^{\alpha} V+1-B}
$$

where $V \equiv A(1-\alpha)(\gamma(1-\tau)+\delta \psi \tau)$. Given the assumptions $A>0,0<\alpha<1$ and $\gamma(1-\tau)+\delta \psi \tau>0$, it follows that $V$ must be strictly positive.

In a similar way, the $\lambda \lambda$ locus can be written as:

$$
\lambda=\frac{k^{\alpha} W}{k^{\alpha} W+1-R}
$$

where $W \equiv A(1-\alpha)(\varepsilon(1-\tau)+v(1-\psi) \tau)$. Here again, $W>0$.

Then, substituting these two expressions in the $k k$ locus yields:

$$
k=\left(\frac{A \beta(1-\alpha)(1-\tau)\left(\frac{k^{\alpha} V}{k^{\alpha} V+1-B}\right)\left(\frac{k^{\alpha} W}{k^{\alpha} W+1-R}\right)}{(1+n)\left(1+\beta\left(\frac{k^{\alpha} V}{k^{\alpha} V+1-B}\right)\left(\frac{k^{\alpha} W}{k^{\alpha} W+1-R}\right)\right)}\right)^{\frac{1}{1-\alpha}}
$$

If we denote the right-hand side as the function $H(k)$, the question of the existence of an equilibrium becomes the search for a fixed point of $H(k)$. It is clear that 0 is a fixed point. But we would like to derive conditions guaranteeing the existence of another fixed point.

For that purpose, we shall follow the method proposed in the Appendix A and show that the function $H(k)$ satisfies the properties (i)-(iv), that is:

(i) $H(0)=0$

(ii) $H^{\prime}(k) \geq 0 \forall k \in[0, \bar{k}]$

(iii) $\lim _{k \rightarrow \bar{k}} H(k) / k<1$

(iv) $\lim _{k \rightarrow 0} H^{\prime}(k)=+\infty$ if $\alpha<\alpha^{*}$.

(i)

$$
H(0)=\left(\frac{A \beta(1-\alpha)(1-\tau) 0}{(1+n)}\right)^{\frac{1}{1-\alpha}}=0
$$

(ii) To show this, we shall assume that there exists an upper bound steadystate $k$, denoted by $\bar{k}$, i.e. a value of $k$ that the steady-state capital never exceeds. Given that the postulated Cobb-Douglas production function satisfies the Inada conditions, there can be no doubt that such an upper bound exists. Moreover, that upper bound is independent from $\phi$ and $\lambda$. Throughout this Appendix, we shall take $\bar{k}=\left(\frac{A \beta(1-\alpha)(1-\tau)}{(1+n)(1+\beta)}\right)^{\frac{1}{1-\alpha}}$ 
In the interval $[0, \bar{k}]$, the first-order derivative of $H$ with respect to $k$ has, under mield conditions, the desired sign. Indeed, a positive $H^{\prime}(k)$ implies:

$k^{2 \alpha}\left(1-\frac{(V W)^{\alpha+1}}{\beta}\right) \leq \frac{(V W)^{\alpha} k^{\alpha} V(1-R)}{\beta}+\frac{(V W)^{\alpha} k^{\alpha} W(1-B)}{\beta}+\frac{(1-B)(1-R)}{\beta}+1$

which is a mild condition.

(iii) When $k$ tends to $\bar{k}$, the $\lim _{k \rightarrow \bar{k}} H(k) / k$ is:

$$
\lim _{k \rightarrow \bar{k}} H(k) / k=\frac{\left(\frac{A \beta(1-\alpha)(1-\tau)\left(\lim _{k \rightarrow \bar{k}} \phi\right)\left(\lim _{k \rightarrow \bar{k}} \lambda\right)}{(1+n)\left(1+\beta\left(\lim _{k \rightarrow \bar{k}} \phi\right)\left(\lim _{k \rightarrow \bar{k}} \lambda\right)\right)}\right)^{\frac{1}{1-\alpha}}}{\left(\frac{A \beta(1-\alpha)(1-\tau)}{(1+n)(1+\beta)}\right)^{\frac{1}{1-\alpha}}}<1
$$

given that $\phi$ and $\lambda$ are bounded by 1 (i.e. their values when $k \rightarrow+\infty$ ), the above ratio remains inferior to 1 as required.

(iv) The $\lim _{k \rightarrow 0} H^{\prime}(k)$ is:

$\frac{C^{1-\alpha}}{1-\alpha} \frac{\left(\left(k^{\frac{3 \alpha-1}{1-\alpha}}\right)\left[(V W)^{\alpha}(1-B)(1-R)\right]^{\frac{1}{1-\alpha}}(\alpha 2 Z)\right)+\left(\beta(V W)^{\frac{1}{1-\alpha}}[(1-B)(1-R)]^{\frac{\alpha}{1-\alpha}}(\alpha 2 Z)\right)\left(k^{\frac{3 \alpha-1}{1-\alpha}}\left(1-k^{2 \alpha}\right)\right)}{(1+n)^{\frac{1-2 \alpha}{1-\alpha}}(1-B)^{\frac{3-\alpha}{1-\alpha}}(1-R)^{\frac{3-\alpha}{1-\alpha}}}$

where $Z \equiv V(1-B) W(1-R)$. It is straightforward to see that, when $k$ tends to zero, $H^{\prime}(k)$ tends to $+\infty$ provided $\alpha<\alpha^{*}=1 / 3$.

By the same rationale as in the basic case, it appears that, under $\alpha<1 / 3$, a non-trivial equilibrium must exist: the function $H(k)$ must intersect the $45^{\circ}$ line at least once on the interval $[0, \bar{k}]$. However, for $\alpha \geq 1 / 3$, one cannot be sure that a non-trivial equilibrium exists.

Regarding the unicity issue, one can see, from the above expression, that, under $\alpha<1 / 3, H^{\prime \prime}(k)$ is strictly negative, so that $H$ is concave, which implies that the non-trivial equilibrium must be, under that condition, unique. 


\section{CESifo Working Paper Series}

(for full list see www.cesifo-group.de)

1716 Chris van Klaveren, Bernard van Praag and Henriette Maassen van den Brink, Empirical Estimation Results of a Collective Household Time Allocation Model, May 2006

1717 Paul De Grauwe and Agnieszka Markiewicz, Learning to Forecast the Exchange Rate: Two Competing Approaches, May 2006

1718 Sijbren Cnossen, Tobacco Taxation in the European Union, May 2006

1719 Marcel Gérard and Fernando Ruiz, Interjurisdictional Competition for Higher Education and Firms, May 2006

1720 Ronald McKinnon and Gunther Schnabl, China's Exchange Rate and International Adjustment in Wages, Prices, and Interest Rates: Japan Déjà Vu?, May 2006

1721 Paolo M. Panteghini, The Capital Structure of Multinational Companies under Tax Competition, May 2006

1722 Johannes Becker, Clemens Fuest and Thomas Hemmelgarn, Corporate Tax Reform and Foreign Direct Investment in Germany - Evidence from Firm-Level Data, May 2006

1723 Christian Kleiber, Martin Sexauer and Klaus Waelde, Bequests, Taxation and the Distribution of Wealth in a General Equilibrium Model, May 2006

1724 Axel Dreher and Jan-Egbert Sturm, Do IMF and World Bank Influence Voting in the UN General Assembly?, May 2006

1725 Swapan K. Bhattacharya and Biswa N. Bhattacharyay, Prospects of Regional Cooperation in Trade, Investment and Finance in Asia: An Empirical Analysis on BIMSTEC Countries and Japan, May 2006

1726 Philippe Choné and Laurent Linnemer, Assessing Horizontal Mergers under Uncertain Efficiency Gains, May 2006

1727 Daniel Houser and Thomas Stratmann, Selling Favors in the Lab: Experiments on Campaign Finance Reform, May 2006

1728 E. Maarten Bosker, Steven Brakman, Harry Garretsen and Marc Schramm, A Century of Shocks: The Evolution of the German City Size Distribution 1925 - 1999, May 2006

1729 Clive Bell and Hans Gersbach, Growth and Enduring Epidemic Diseases, May 2006

1730 W. Bentley MacLeod, Reputations, Relationships and the Enforcement of Incomplete Contracts, May 2006 
1731 Jan K. Brueckner and Ricardo Flores-Fillol, Airline Schedule Competition: ProductQuality Choice in a Duopoly Model, May 2006

1732 Kerstin Bernoth and Guntram B. Wolff, Fool the Markets? Creative Accounting, Fiscal Transparency and Sovereign Risk Premia, May 2006

1733 Emmanuelle Auriol and Pierre M. Picard, Government Outsourcing: Public Contracting with Private Monopoly, May 2006

1734 Guglielmo Maria Caporale and Luis A. Gil-Alana, Modelling Structural Breaks in the US, UK and Japanese Unemployment Rates, May 2006

1735 Emily J. Blanchard, Reevaluating the Role of Trade Agreements: Does Investment Globalization Make the WTO Obsolete?, May 2006

1736 Per Engström and Bertil Holmlund, Tax Evasion and Self-Employment in a High-Tax Country: Evidence from Sweden, May 2006

1737 Erkki Koskela and Mikko Puhakka, Cycles and Indeterminacy in Overlapping Generations Economies with Stone-Geary Preferences, May 2006

1738 Saku Aura and Thomas Davidoff, Supply Constraints and Housing Prices, May 2006

1739 Balázs Égert and Ronald MacDonald, Monetary Transmission Mechanism in Transition Economies: Surveying the Surveyable, June 2006

1740 Ben J. Heijdra and Ward E. Romp, Ageing and Growth in the Small Open Economy, June 2006

1741 Robert Fenge and Volker Meier, Subsidies for Wages and Infrastructure: How to Restrain Undesired Immigration, June 2006

1742 Robert S. Chirinko and Debdulal Mallick, The Elasticity of Derived Demand, Factor Substitution and Product Demand: Corrections to Hicks’ Formula and Marshall's Four Rules, June 2006

1743 Harry P. Bowen, Haris Munandar and Jean-Marie Viaene, Evidence and Implications of Zipf's Law for Integrated Economies, June 2006

1744 Markku Lanne and Helmut Luetkepohl, Identifying Monetary Policy Shocks via Changes in Volatility, June 2006

1745 Timo Trimborn, Karl-Josef Koch and Thomas M. Steger, Multi-Dimensional Transitional Dynamics: A Simple Numberical Procedure, June 2006

1746 Vivek H. Dehejia and Yiagadeesen Samy, Labor Standards and Economic Integration in the European Union: An Empirical Analysis, June 2006

1747 Carlo Altavilla and Paul De Grauwe, Forecasting and Combining Competing Models of Exchange Rate Determination, June 2006 
1748 Olaf Posch and Klaus Waelde, Natural Volatility, Welfare and Taxation, June 2006

1749 Christian Holzner, Volker Meier and Martin Werding, Workfare, Monitoring, and Efficiency Wages, June 2006

1750 Steven Brakman, Harry Garretsen and Charles van Marrewijk, Agglomeration and Aid, June 2006

1751 Robert Fenge and Jakob von Weizsäcker, Mixing Bismarck and Child Pension Systems: An Optimum Taxation Approach, June 2006

1752 Helge Berger and Michael Neugart, Labor Courts, Nomination Bias, and Unemployment in Germany, June 2006

1753 Chris van Klaveren, Bernard van Praag and Henriette Maassen van den Brink, A Collective Household Model of Time Allocation - a Comparison of Native Dutch and Immigrant Households in the Netherlands, June 2006

1754 Marko Koethenbuerger, Ex-Post Redistribution in a Federation: Implications for Corrective Policy, July 2006

1755 Axel Dreher, Jan-Egbert Sturm and Heinrich Ursprung, The Impact of Globalization on the Composition of Government Expenditures: Evidence from Panel Data, July 2006

1756 Richard Schmidtke, Private Provision of a Complementary Public Good, July 2006

1757 J. Atsu Amegashie, Intentions and Social Interactions, July 2006

1758 Alessandro Balestrino, Tax Avoidance, Endogenous Social Norms, and the Comparison Income Effect, July 2006

1759 Øystein Thøgersen, Intergenerational Risk Sharing by Means of Pay-as-you-go Programs - an Investigation of Alternative Mechanisms, July 2006

1760 Pascalis Raimondos-Møller and Alan D. Woodland, Steepest Ascent Tariff Reforms, July 2006

1761 Ronald MacDonald and Cezary Wojcik, Catching-up, Inflation Differentials and Credit Booms in a Heterogeneous Monetary Union: Some Implications for EMU and new EU Member States, July 2006

1762 Robert Dur, Status-Seeking in Criminal Subcultures and the Double Dividend of ZeroTolerance, July 2006

1763 Christa Hainz, Business Groups in Emerging Markets - Financial Control and Sequential Investment, July 2006

1764 Didier Laussel and Raymond Riezman, Fixed Transport Costs and International Trade, July 2006 
1765 Rafael Lalive, How do Extended Benefits Affect Unemployment Duration? A Regression Discontinuity Approach, July 2006

1766 Eric Hillebrand, Gunther Schnabl and Yasemin Ulu, Japanese Foreign Exchange Intervention and the Yen/Dollar Exchange Rate: A Simultaneous Equations Approach Using Realized Volatility, July 2006

1767 Carsten Hefeker, EMU Enlargement, Policy Uncertainty and Economic Reforms, July 2006

1768 Giovanni Facchini and Anna Maria Mayda, Individual Attitudes towards Immigrants: Welfare-State Determinants across Countries, July 2006

1769 Maarten Bosker and Harry Garretsen, Geography Rules Too! Economic Development and the Geography of Institutions, July 2006

1770 M. Hashem Pesaran and Allan Timmermann, Testing Dependence among Serially Correlated Multi-category Variables, July 2006

1771 Juergen von Hagen and Haiping Zhang, Financial Liberalization in a Small Open Economy, August 2006

1772 Alessandro Cigno, Is there a Social Security Tax Wedge?, August 2006

1773 Peter Egger, Simon Loretz, Michael Pfaffermayr and Hannes Winner, Corporate Taxation and Multinational Activity, August 2006

1774 Jeremy S.S. Edwards, Wolfgang Eggert and Alfons J. Weichenrieder, The Measurement of Firm Ownership and its Effect on Managerial Pay, August 2006

1775 Scott Alan Carson and Thomas N. Maloney, Living Standards in Black and White: Evidence from the Heights of Ohio Prison Inmates, 1829 - 1913, August 2006

1776 Richard Schmidtke, Two-Sided Markets with Pecuniary and Participation Externalities, August 2006

1777 Ben J. Heijdra and Jenny E. Ligthart, The Transitional Dynamics of Fiscal Policy in Small Open Economies, August 2006

1778 Jay Pil Choi, How Reasonable is the 'Reasonable' Royalty Rate? Damage Rules and Probabilistic Intellectual Property Rights, August 2006

1779 Ludger Woessmann, Efficiency and Equity of European Education and Training Policies, August 2006

1780 Gregory Ponthiere, Growth, Longevity and Public Policy, August 2006 